\title{
Carnitine Enigma: From Antioxidant Action to Vitagene Regulation. Part 2. Transcription Factors and Practical Applications
}

Keywords: Carnitine; Antioxidant; Nrf2; NF-KB; PPARs; Vitagenes; Stress; Poultry; Pigs

\section{Abstract}

A growing interest has been shown in the potential uses of carnitine in medical practice and animal/poultry industry. The molecular mechanisms accounting for the positive effect of LC on livestock animals are not yet fully understood but many protective effects of LC in various stress conditions reported in literature, have been related to its antioxidant action. Based on the analysis of the recent publications presented in the review it could be concluded that antioxidant actions of carnitine are associated to much extent with redox signaling in the cell. Indeed, LC is shown to upregulate Nrf2 and PPARs and downregulates NF-KB leading to anti-apoptotic and anti-inflammation actions of carnitine. In fact, Nrf2-mediated synthesis of antioxidant enzymes, including SOD, GSH-Px, GR, GST and GSH, in response to carnitine supplementation could be a main driving force of antioxidant action of carnitine and its derivatives. Furthermore, LC and its derivatives are shown to affect vitagene networks resulting in increased adaptive ability to stresses via additional synthesis of protective molecules, including heat shock proteins ( $\mathrm{HO}-1)$, upregulating sirtuins, thioredoxins and SOD. It seems likely that in biological system in vivo the interactions of the aforementioned mechanisms provide an important place for carnitine to be a crucial part of the integrated antioxidant systems of the animal and human body. Furthermore, direct scavenging ROS and chelating properties of carnitine would be very much relevant to the antioxidant system of the gut. Taking into account low carnitine content in grains and poultry and pig diet formulations with limited amounts of animal proteins, carnitine requirement and possible inadequacy in commercial poultry and pig nutrition should receive more attention. Furthermore, protective roles of carnitine in stress conditions of commercial poultry and pig production, including its immunomodulating properties, are of great importance. Therefore, a development of carnitine-containing antioxidant compositions supplying via drinking water seems to be an important way forward in decreasing the detrimental consequence of various stresses in poultry and pig production.

\section{Abbreviations}

ALC: Acetyl-L-Carnitine; AREs: Antioxidant Response Elements; BSA: Bovine Serum Albumin; b.w.: Body Weight; CoQ: Coenzyme Q; eNOS: Endothelial Nitric Oxide Synthase; FFA: Free Fatty Acids; $\gamma$ GCS: $\gamma$-Glutamate Cysteine Ligase; GRa: Glucocorticoid Receptor- $\alpha$; GR: Glutathione Reductase; GSH: Glutathione; GSHPx: Glutathione Peroxidase; GST: Glutathione Transferase; HO: Heme Oxygenase; HSP: Heat Shock Protein; IL: Interleukin, ICAM1: Intercellular Adhesion Molecule 1; IFN- $\gamma$ : Interferon Gamma; i.p.: Intraperitoneal; LA: Lipoic Acid; LC: L-Carnitine; L-NAME: N-nitroL-arginine Methyl Ester; LPS: Lipopolysaccharide; MCP-1: Monocyte Chemoattractant Protein-1; MDA: Malondialdehyde; NF- $\mathrm{B}$ : Nuclear Factor-kappa B; Nrf2: Nuclear Factor-erythroid-2-related Factor 2; NQO1- NAD(P)H: Quinone-oxidoreductase-1; PHA: Phytohemagglutinin; PHS: Pulmonary Hypertension Syndrome,

\section{Journal of}

Veterinary Science \& Medicine

\author{
Peter F. Surai ${ }^{1-5^{*}}$ \\ 'Department of Microbiology and Biochemistry, Faculty of \\ Veterinary Medicine, Trakia University, Stara Zagora 6000, \\ Bulgaria \\ ${ }^{2}$ Department of Animal Nutrition, Faculty of Agricultural and \\ Environmental Sciences, Szent Istvan University, Gödöllo H-2103, \\ Hungary \\ ${ }^{3}$ Department of Veterinary Expertise and Microbiology, Faculty of \\ Veterinary Medicine, Sumy National Agrarian University, Sumy \\ 40021, Ukraine \\ ${ }^{4}$ Odessa National Academy of Food Technology, Odessa 65039, \\ Ukraine \\ ${ }^{5}$ Russian Academy of Science, Moscow, Russia
}

*Address for Correspondence

Peter F. Surai, Department of Microbiology and Biochemistry, Faculty of Veterinary Medicine, Trakia University, Stara Zagora 6000, Bulgaria, E-mail: psurai@feedfood.co.uk

Submission: 03 August, 2015

Accepted: 03 November, 2015

Published: 21 November, 2015

Copyright: $\odot 2015$ Surai PF. This is an open access article distributed under the Creative Commons Attribution License, which permits unrestricted use, distribution, and reproduction in any medium, provided the original work is properly cited.

Reviewed \& Approved by: Dr. Mark Brown, Professor, Department of Clinical Sciences, Colorado State University, USA

PGI2: Prostaglandin I2 (prostacyclin); PPARa: Peroxisome Proliferator Activated Receptor Alpha; RGCs: Retinal Ganglion Cells, ROS: Reactive Oxygen Species; RNS: Reactive Nitrogen Species; SOD: Superoxide Dismutase; TNFa: Trx-thioredoxins.

\section{Introduction}

For the last 30 years carnitine has received considerable attention in medical sciences and animal production due to its diverse functions and beneficial effects in various stress conditions. Carnitine functions in the body are diverse and include: a) transport of activated long-chain fatty acids from the cytosol to the mitochondrial matrix for oxidation and energy production; $b$ ) transfer of the products of peroxisomal $\beta$-oxidation, including acetyl-CoA, to the mitochondria for oxidation to $\mathrm{CO}_{2}$ and $\mathrm{H}_{2} \mathrm{O}$ in the Krebs cycle; c) modulation of the acyl-CoA/CoA ratio; d) storage of energy as acetyl-carnitine; e) modulation of toxic effects of poorly metabolized acyl groups by excreting them as carnitine esters; f) preservation of membrane integrity and mitochondria functions as well as apoptosis inhibition; g) participation in redox-signaling and vitagene activation; h) maintenance of the antioxidant systems of the body $[1,2]$. In the first part of the review [2] it has been clearly shown that antioxidant action of carnitine were, firstly, related to free radical scavenging and metal chelating, which could be relevant to the maintenance of the antioxidant-prooxidant balance in the gut. Secondly, and more importantly, carnitine participates in mitochondria integrity maintenance and prevents free radical formation in the electron transfer chain in mitochondria and inhibits activities of some ROSgenerating enzymes. However, it seems likely that main antioxidant effect of carnitine is mediated via its participation in redox signaling 
and transcription factor regulation as well as affecting vitagene networks. Therefore, the main aim of the review is to analyse possible roles of LC and its derivatives in regulation of transcription factors and vitagene networks with a special attention to possible practical applications of the protective carnitine properties in poultry production.

\section{Oxidative Stress and Transcription Factors}

Oxidation-reduction (redox) based regulation of gene expression is a fundamental regulatory mechanism in cell biology acting at the cell-signaling level. Since ROS are damaging to many biological molecules, the antioxidant systems are responsible for prevention of the damages. However, a basal level of oxidative stress is essential for cell adaptation and survival. Therefore, a moderate level of oxidative stress can create adaptive responses and improve adaptive ability to stressful challenges/conditions [3]. Indeed, in animals, redoxsignaling pathways use ROS as signaling molecules to activate genes responsible for regulation of various functions including growth, differentiation, proliferation and apoptosis. Furthermore, the antioxidant defence systems are also under regulation by various transcription factors [4-7]. These pathways operate in coordinated manner being critically important for animal adaptation to various stresses. In particular, they include Keap1/Nrf2, NF- $\kappa B$, PPARs, MAPK, AP1, etc. [8]. In recent years great attention has been paid to a basic leucine zipper transcription factor, Nuclear factor-erythroid-2(NF-E2-) related factor 2 (Nrf2) and NF- $\kappa \mathrm{B}$.

\section{Transcription factor Nrf2}

It is known that Nrf2 is the redox-sensitive master regulator of oxidative stress signaling and oxidative stress responses and is critical for cell survival in stressful conditions [9]. It has been shown that the Nrf2 antioxidant response pathway is an important player in the cellular antioxidant defense. Indeed, it is responsible for activation of a variety of genes involved in early defence reactions of higher organisms [10,11]. High expression of Nrf2 in organs that face environmental stresses including lungs and small intestine [12] is a confirmation of its importance in stress adaptation processes. Clearly, Nrf2 has a significant role in adaptive responses to oxidative stress being involved in the induction of the expression of various antioxidant molecules to combat oxidative and electrophilic stress [13-16].

It is suggestive that under normal physiological conditions, Nrf2 is kept in the cytoplasm by forming an inactive complex with the negative regulator, Kelch-like-ECH-associated protein 1 (Keap1), which is anchored to the actin cytoskeleton. In fact, Keap1 sequesters Nrf2 in the cytoplasm and forwards it to a Cul3-based E3 ligase with the following rapid ubiquitin-proteasome degradation leading to a short (about $20 \mathrm{~min}$ ) half-life of Nrf-2 under physiological conditions (for review see [17]). It seems likely that, Keap-1 is an important cellular redox sensor and upon exposure to oxidative or electrophilic stress, critical cysteine thiols of Keap1 are modified/oxidised and Keap1 loses its ability to ubiquitinate Nrf2 resulting in preventing its degradation. There are also other ways of Nrf2 activation. For example, phosphorylation of Nrf2 at specific serine and/or tyrosine residues also causes an Nfr2-Keap1 dissociation resulting in Nrf2 release and translocation to nucleus, where it combines with a small musculoaponeurotic fibrosarcoma protein called Maf to form a heterodimer [18]. Indeed, by binding to the ARE in the upstream promoter region of genes encoding various antioxidant molecules, Nrf2 regulates the expression of antioxidant proteins, thiol molecules and other protective molecules. This includes enzymes of the first line of the antioxidant defence, namely SOD, GSH-Px and Catalase, detoxification enzymes (HO-1, NQO1, and

GST), GSH-related proteins ( $\gamma$-GCS), NADPH-producing enzymes and others stress-response proteins contributing to preventing oxidative and inflammatory damages $[19,20]$. In fact, hundreds of cytoprotective genes are regulated by Nrf2 [12] and gene products (proteins) are involved in the maintenance and responsiveness of the cellular antioxidant systems. Indeed, an orchestrated change in gene expression via Nrf2 and the ARE is a key mechanism of a protective effect against oxidative stress [21]. It is suggestive that, Nrf2 is controlled through a complex transcriptional/epigenetic and post-translational network that provides regulatory mechanisms ensuring Nrf2 activity increases in response to redox disturbances, inflammation, growth factor stimulation and nutrient/energy fluxes orchestrating adaptive responses to diverse forms of stress [22].

As mentioned above, there is a range of Nrf2 activating mechanisms, including stabilization of $\mathrm{Nrf} 2$ via Keap1 cysteine thiol modification and phosphorylation of $\mathrm{Nrf} 2$ by upstream kinases $[23,24]$. It is proven that effects of Nrf2 on the adaptive ability of cells is quite broad and is beyond activation of synthesis of antioxidant molecules. Indeed, Nrf2 also contributes to homeostasis by upregulating the repair and degradation of damaged macromolecules, and by modulating intermediary metabolism conducting directs metabolic reprogramming during stress [20].

Recently molecular mechanisms of regulating roles of transcription factors in cellular adaptation to stress have been extensively studied. In particular, it has been suggested that low intensity oxidative stress is predominantly sensed by Keap1/Nrf2 system [8] with the following downstream up-regulation of the protective $\mathrm{AO}$ genes. It is interesting to note that intermediate oxidative stress also increases the activity of antioxidant enzymes, but mainly via NF- $\kappa \mathrm{B}$ and AP-1 pathways [8]. Furthermore, at both, low and intermediate intensity oxidative stresses, MAP-kinases and other kinases seem to be involved in signal sensing and cellular response, leading to enhanced antioxidant potential [20]. Emerging evidence clearly indicates that Nrf2 can interact with other transcription factors, including heat shock factor (Hsf1; [25]) to provide additional options for AO system regulation. As mentioned above, the Nrf2 stress pathway intimately communicates with mitochondria to maintain cellular homeostasis during oxidative stress [12].

Carnitine and Nrf2 regulation: The aforementioned evidences indicate that main protective effects of LC and ALC were associated with preservation or increased activity of antioxidant enzymes and GSH in various tissues affected by stress conditions. The mechanisms involved in the regulation of antioxidant enzymes by LC in vivo have not been precisely determined yet. However, it seems likely that transcription factors, including Nrf2, are involved in this regulation. First, it was shown in vitro that treatment of astrocytes with ALC (30-100 $\mu \mathrm{M})$ induces HO-1 in a dose- and time-dependent manner 
and that this effect was associated with up-regulation of HSP60 as well as high expression of the redox-sensitive transcription factor Nrf2 in the nuclear fraction of treated cells [26]. Adipocytes cultured in the presence of LA and/or ALC $(0.1,1$ and $10 \mu \mathrm{M})$ for $24 \mathrm{~h}$ were characterised by increased expression of Nrf2 [27]. However, the treatments with LA or ALC alone at the same concentrations showed little effect on mitochondrial function and Nrf2 expression. Nrf2 regulated augmented antioxidant response on administration of ALC was shown to be a crucial factor in ameliorating hypoxia-induced neurodegeneration and memory impairment [28]. Indeed, a decrease in free radical generation, lipid peroxidation and protein oxidation was also observed along with a concomitant increase in thioredoxin and reduced glutathione levels on administration of ALC during exposure to hypobaric hypoxia. It was also demonstrated that administration of ALC to hypoxic rats effectively protected hippocampal neurons from mitochondrial dysfunction, excitotoxicity, and neurodegeneration [29]. Furthermore, ALC caused increased expression of Nrf2 in the nuclear fraction of rats with a concomitant decrease in expression of the protein in the cytosolic fraction. In addition, ALC administration resulted in PPAR- $\gamma$ coactivator- $1 \alpha$ and nuclear respiratory factor1 -induced mitochondrial biogenesis, the expression of which was regulated by an extracellular-related kinase-nuclear factor erythroid 2-related factor 2 (ERK-Nrf2)-mediated mechanism. Indeed, ALCadministered hypoxic rats showed increased DNA-binding ability of Nrf2 along with upregulation of Nrf1. The authors provided evidence for Nrf2-mediated regulation of mitochondrial biogenesis through Nrf1 following ALC supplementation [29]. Administration of LC to L-NAME-induced hypertensive rats prevented decrease in Nrf2 expression in the renal cortex [30]. Indeed, it was shown that LC can also significantly protect ischemia-reperfusion injury due to the overexpression of HO-1 induced by activated Keapl-Nrf2-ARE signaling pathway [31]. Furthermore, ALC administration to human lens epithelial cells treated with homocysteine, restored (increased) the levels of antioxidant proteins, including SOD, GSH-Px, Catalase, Nrf2, Keap1 and GSH [32]. Indeed, the aforementioned data clearly indicate modulating effects of LC and its derivatives on the Nrf2 system in various tissues.

\section{Transcription factor NF- $\mathrm{kB}$}

The nuclear factor-kappa $\mathrm{B}(\mathrm{NF}-\mathrm{\kappa} \mathrm{B})$ is an inducible transcription factor that regulates many cellular processes including immunity and inflammation. NF- $\kappa \mathrm{B}$ consists of a group of five related proteins that are capable of binding to DNA. This transcription factor is activated by a wide range of stimuli including oxidative stress. It has been shown that NF- $\kappa B$ regulates the transcription of many different genes, including pro-inflammatory cytokines and leukocyte adhesion molecules, acute phase proteins and anti-microbial peptides [33-35]. There are some similarities in regulation of Nrf2 and NF- $\mathrm{kB}$. For example, in physiological conditions, NF- $\mathrm{kB}$ is found in cytoplasm in an inactive state associated with the inhibitory I $\mathrm{K} B$ proteins preventing its binding to target sites. It has been proven that activation of NF$\kappa \mathrm{B}$ is an effective mechanism of host defense against infection and stress [36]. As a result of action of cytokines and other stressors, IкB proteins are rapidly phosphorylated by IKB kinase on specific serine residues, with following ubiquitination, and degradation by the $26 \mathrm{~S}$ proteasome. The following release of NF- $\mathrm{KB}$ and its translocation to the nucleus is responsible for the transcription of target genes, responsible for cell survival and involved with inflammation, immunity, apoptosis, cell proliferation and differentiation [37]. NF$\kappa \mathrm{B}$ transcription factors, such as $\mathrm{p} 65$, can combine to form hetero- and homo-dimers of different composition, providing a tool for effective regulation of different sets of gene targets [38]. There is a range of additional stimuli implicated into the NF- $\mathrm{KB}$ activation including, cell-surface receptors, inhibitory $\mathrm{\kappa B}$ kinases, IB proteins, and factors that are involved in the posttranslational modification of the Rel proteins, etc. [33-37]. Accumulating evidence indicates that there is a complex interplay/crosstalk between Nrf2 and NF- $\kappa \mathrm{B}$ pathways. For example, several Nrf2 activators can inhibit NF- $\kappa B$ pathway. NF$\kappa \mathrm{B}$ may also directly antagonize the transcriptional activity of $\mathrm{Nrf2}$ (for review see [33]). In recent years, several compounds, including LC, have been shown to have inhibitory activities against multiple components of NF- $\kappa$ B activation pathway.

Carnitine and NF- $\kappa \mathrm{B}$ regulation: Initially, it was shown that ALC selectively induces the expression of metabotropic glutamate receptor 2 by acting as a donor of acetyl groups, hyperacetylating p65/RelA and thus changing the activity of the NF- $\kappa \mathrm{B}$ family of transcription factors [39]. Indeed, the in vitro proneurogenic effects of ALC appear to be mediated by affecting the NF-kB pathway and in particular by p65 acetylation, and subsequent NF- $\mathrm{kB}$-mediated upregulation of metabotropic glutamate receptor 2 (mGlu2) expression [40]. In vivo, PLC treatment for 15 days after injury resulted in a reduction of relative rat aortic intimal volume, an increase of apoptosis, Bax upregulation without changing the $\mathrm{Bcl}-2$ level, and a reduction of NF$\kappa \mathrm{B}$ [41]. The authors also showed that the PLC-induced attenuation of NF- $\kappa \mathrm{B}$ activity in intimal cells was due to the increase of I $\mathrm{KB}-\alpha$ bioavailability, as the result of a parallel induction of IкB- $\alpha$ synthesis and reduction of phosphorylation and degradation. LC (8.3-13.1 $\mathrm{mM}$ ) was found to significantly inhibit LPS-induced transactivation of NF-kB in LPS-stimulated macrophage cells [42]. Recently, it has been confirmed that the molecular regulation of antioxidant enzymes through an inhibition of the renin-angiotensin system and a modulation of the NF- $\mathrm{KB} / \mathrm{I} \kappa \mathrm{B}$ system seems to be responsible for the antioxidant effect of carnitine [43]. A decrease in the expression of transcription factors Nrf2 and PPAR $\alpha$, together with an increase in NF- $\kappa B$ expression, was observed in the renal cortex of L-NAMEinduced hypertensive rats compared with control rats (0.3-, 0.8-, and 13 -fold, respectively). The simultaneous administration of LC attenuated these alterations, reaching values similar to those found in control rats $[30,44,45]$. Recently it has been shown that LC reduces NF- $\mathrm{KB}$ transactivational activity and then the production of TNFa, ICAM1, and MCP-1 in carboplatin-treated renal tubular cells [46]. Therefore inhibitory effects of carnitine on the NF- $\kappa B$ activated by various stress factors could be an important protective mechanism of the antioxidant defences in the body. It has also been reported that LC can activate another transcription factor, namely the peroxisome proliferator activated receptor alpha (PPAR $\alpha)$.

\section{Transcription factors PPARs}

The peroxisome proliferator-activated receptors (PPARs) are a group of three nuclear receptor isoforms, PPAR $\gamma, \operatorname{PPAR} \alpha$, and PPAR $\delta / \beta$, identified in the 1990s in rodents and named after their property of peroxisome proliferation [47]. PPARs are ligandregulated transcription factors that control gene expression by 
binding to specific response elements (PPREs) within promoters and they affect various important cellular events including proliferation, differentiation, and apoptosis [48]. PPARs are shown to form a heterodimer with retinoid-X receptor (RXR) and bind a peroxisome proliferator response element (PPRE) on target genes [49]. It is proven that PPARs control expression of various genes that are crucial for lipid and carbohydrate metabolism being 'master' transcriptional regulators of nutrient metabolism and energy homeostasis that modulate the expression of unique constellations of genes [50]. In particular, PPAR $\gamma$ is considered to be the master transcription factor for adipogenesis, while PPARa mainly distributes in the tissue with a high efficiency of mitochondrial fatty acid oxidation, which highly expresses in the liver whereas $\mathrm{PPAR} \beta / \delta$ expression is found to be very high in the small intestine and keratinocyte [51]. It seems likely that expression levels of PPARs are subject to regulation by diets and nutrient status in a tissue-dependent manner and the activities of PPARa and PPAR (gamma) can be regulated by phosphorylation [52]. It is also known that the three PPAR members share a high degree of homology however; they differ in tissue distribution, ligand specificity, and physiological roles [48]. In fact, all three PPARs play essential roles in lipid and fatty acid metabolism by directly binding to and modulating genes involved in fat metabolism [53]. Recently, a considerable number of papers have reviewed PPARs importance in regulation of various physiological and biochemical processes within the body $[47,50,51,54-57]$ and the evolutionary pattern and regulation characteristics of PPARs have been analysed [58]. In particular, PPAR $\alpha$ is activated by adiponectin and could inhibit NF- $\kappa B$ pathway, while PPAR (gamma) enhances insulin action, FFA oxidation, adiponectin secretion, and inhibits secretion of proinflammatory cytokines [57]. It seems likely that PPAR signaling is a part of the body's antioxidant system playing an important role in various stress conditions. In fact, the antioxidant effect of PPARa has been shown and PPAR-responsive elements (PPREs) have been identified in the promoter regions of several antioxidant genes, including catalase and $\mathrm{Cu}^{2+} \mathrm{Zn}^{2+}$-SOD. Therefore, PPARa can bind to PPREs to promote the expression of antioxidants to inhibit oxidative stress [59-62] having a regulatory effect over the production of oxidative, proinflammatory and profibrotic mediators [63]. Furthermore, induction of PPARa by PPARa agonist WY14643 treatment ameliorated the oxidative stress and severity of liver injury and restored expression of genes altered by ethanol treatment [64].

A synergistic relationship between PPAR-signaling and the $\mathrm{HO}$-system exists related to the regulation of various physiological functions. For example, PPARs suppress inflammation/oxidative stress and attenuate excessive immune responses, while agonists of PPAR $\gamma$ and PPARa have been shown to upregulate the HOsystem. At the same time, the HO-system can enhance PPARa, and potentiates the expression and activity of PPAR $\gamma$. Similar to PPARs, the HO-system has been shown to suppress inflammation/oxidative stress and modulate immune response [56].

Carnitine and PPARs regulation: The experimental evidence is accumulating from current studies in rats, mice and pigs to establish an essential role for PPARa in the regulation of carnitine homeostasis [65]. Indeed, an essential role for PPARa in the regulation of carnitine uptake and carnitine biosynthesis in rodents and pigs has been clearly established. For example, genes encoding proteins involved in carnitine uptake and carnitine biosynthesis are transcriptionally regulated by PPAR $\alpha$ [65]. On the other hand, molecular mechanisms of carnitine action, including its antioxidant functions, can also be mediated via PPARs. In fact, PPARa protein levels in the nucleus of murine liver cells increase constantly after LC supplementation and it was shown that transcription levels of the PPAR-binding protein (PPARbp) are also inducible by LC [66]. Indeed, the activation of PPARa is considered to play an important role in inhibiting the NF$\kappa \mathrm{B}$-induced expression of proinflammatory mediators, including vascular cell adhesion molecule-1, interleukin (IL)-6, endothelin-1, and tissue factor in various cells $[46,67]$. For example, in renal tubular cells an anti-apoptotic effect of LC through PGI2-mediated PPAR-a activation has been reported. In fact, it was found that in NRK-52E cells LC increased PPARa activity more than 5 -fold. These results reveal the crucial role of PPARa activation in the LC protective function on gentamicin-induced apoptosis in NRK-52E cells [68]. In fact, LC prevents carboplatin-mediated apoptosis through AMPKmediated PPAR $\alpha$ activation [46]. LC ameliorates colonic cancer cachexia in mice by regulating the expressions of PPAR $\alpha$ and PPAR $\gamma$. Indeed, LC supplementation significantly decreased expression of proinflammatory mediators, namely TNF- $\alpha$ and IL-6, and increased mRNA and protein expressions of PPARa and PPAR $\gamma$ in mice [69]. Carnitine also regulates myocardial metabolism by increasing expression of PPAR $\alpha$ in alcoholic cardiomyopathy [70]. As mentioned above, a decrease in the expression of PPAR $a$ was observed in the renal cortex of L-NAME-induced hypertensive rats and the simultaneous administration of LC attenuated these alterations, reaching values similar to those found in control rats $[30,44,45]$. From in vivo and in vitro studies it is obvious that protective effects of LC against hypertension-associated renal fibrosis occur in a PPAR$\gamma$-dependent manner [45]. The authors suggested that the beneficial effect of LC supplementation was associated with upregulation of both antioxidant enzymes and eNOS, and with a downregulation of both NADPH oxidase and RAS components. It seems likely that PPARa plays an important role in LC anti-apoptotic effect in renal tubular cells [71]. It is important to emphasize that LC not only positively regulated the pathways involved in oxidative stress defence but also improved AKT activation and downstream cellular signaling pathways involved in skeletal muscle atrophy process prevention [72]. Clearly effect of LC on PPARs was well demonstrated in various model system and need further investigation.

\section{Effect of Carnitine on Vitagene Network}

Considering molecular mechanisms of antioxidant protective action of carnitine it is necessary to consider its possible involvement in vitagene regulation. Indeed, it has been suggested that carnitine can affect signaling pathways that result in activation of vitagene network encoding survival proteins and affecting redox-sensitive intracellular pathways [73]. The term "vitagene" was introduced in 1998 by Rattan and later vitagene concept has been further developed and modified by Calabrese and colleagues [73-89] (Table 1). According to Calabrese et al. the term vitagenes refers to a group of genes that are strictly involved in maintenance and preservation of cellular homeostasis during stress conditions and the vitagene family includes heat shock proteins (HSPs), heme oxygenase-1 (HSP32, HO1), HSP60 and HSP70, the thioredoxins (Trx)/thioredoxin reductase (TrxR) system and sirtuins $[75,85]$. The list of potential candidates to 
Citation: Surai PF. Carnitine Enigma: From Antioxidant Action to Vitagene Regulation Part 2. Transcription Factors and Practical Applications. J Veter Sci Med. 2015;3(2): 17.

Table 1: Major components of the vitagene network (adapted from [2,74,75])

\begin{tabular}{|c|c|}
\hline Molecular level & Cellular level \\
\hline AO defense & Cell proliferation \\
\hline DNA-repair systems & Cell differentiation \\
\hline Transfer of genetic information & Stability of cell membrane \\
\hline Stress protein synthesis & Stability of intracellular milieu \\
\hline Proteosomal function & Macromolecular turnover \\
\hline Tissue and organ level & $\begin{array}{c}\text { Physiological and redox control } \\
\text { level }\end{array}$ \\
\hline $\begin{array}{l}\text { Neutralization and removing toxic } \\
\text { chemicals }\end{array}$ & Stress response \\
\hline Tissue regeneration and wound healing & Hormonal response \\
\hline Tumor suppression & Immune response \\
\hline \multirow[t]{2}{*}{ Cell death and cell replacement } & Thermoregulation \\
\hline & Neuronal response \\
\hline
\end{tabular}

vitagene family is growing. In particular, special attention should be paid to SOD, a major inducible enzyme of the first level of antioxidant defence, which can meet selecting criteria to be included into the vitagene family [90]. The products of the vitagenes are responsible for detecting and controlling diverse forms of stress and cell injuries. The molecular mechanisms of the vitagene network operation have been reviewed in recently published comprehensive reviews [84-88] proving an essential regulatory role of the vitagene network in cell and whole organism adaptation to various stresses.

\section{HO-1 and other HSPs}

First, it was shown in vitro that ALC $(30-100 \mu \mathrm{M})$ induces vitagene HO- 1 in astrocytes in a dose- and time-dependent manner. This effect was associated with up-regulation of another vitagene HSP60 [91]. Similarly, ALC (150 mg/kg b.w orally for 4 months) induced vitagenes HO-1, HSP70 and SOD-2 in senescent rats. This protective effect of ALC was associated with other changes: upregulation of GSH levels, prevention of age-related changes in mitochondrial respiratory chain complex expression, and decrease in protein carbonyls and HNE formation [92]. In an in vitro study with human endothelial cells in culture carnitine and its acyl derivatives (at 0.5-2 $\mathrm{mM}$ ) were shown to increase gene and protein expression of HO-1 [93]. Similarly, in humans and in an animal model it was shown that carnitine-mediated improvement in response to erythropoietin involves induction of HO-1 [94]. ALC $100 \mu \mathrm{M}$ was also effective in primary cortical neuronal cultures: significantly attenuating amyloid-beta peptide 1-42-induced cytotoxicity, protein oxidation, lipid peroxidation, and apoptosis in a dose-dependent manner by upregulation of HSPs [95]. It seems likely that ALC exerted protective effects against oxidative stress in part by up-regulating the levels of GSH and HSPs. Indeed, LC treatment can increase level of HO-1 in the retinal ganglion cells [96]. It was shown that LC $(50 \mu \mathrm{M}, 100$ $\mu \mathrm{M}$ and $200 \mu \mathrm{M})$ had protective effects on high glucose-induced oxidative stress in the retinal ganglion cells (RGCs). Indeed, in high glucose stimulated RGCs, LC treatment was associated with an increased level of Nrf2, HO- 1 and $\gamma$-glutamyl cysteine synthetase [96]. Furthermore, ALC administration to human lens epithelial cells treated with homocysteine had a protective effect indicative by restored (increased) levels of antioxidant proteins, including SOD, GSH-Px, Catalase, Nrf2, Keap1 and GSH [32]. Therefore, LC and its derivatives can perform their antioxidant function via activating $\mathrm{HO}$ 1. Indeed, HO induction occurs together with the induction of other heat shock proteins during various stressful conditions. Particularly, manipulation of endogenous cellular defence mechanisms, via the heat shock response, through nutritional antioxidants, including carnitine, may represent an innovative approach to therapeutic intervention in diseases [89] and protection against stresses. Indeed, by maintaining or recovering the activity of vitagenes, it is possible to improve adaptive ability of animals/poultry to withstand various stresses.

\section{Sirtuins}

It seems likely that carnitine can affect sirtuins, another vitagene playing an important role in cell adaptation to various stresses. In fact, both oxidative stress and mitochondrial damage are associated with reduced levels of renal sirtuin 3. Therefore, as expected, treatment with ALC restored SIRT3 expression and activity, improved renal function, and decreased tubular injury in mice [97]. It has been shown that ALC and sirtuins together affect mitochondria acetylation/deacetylation and thereby have the potential to regulate the cellular redox state, energy homeostasis and cell adaptation to stress [98]. From the aforementioned data it is clear that carnitine can be considered as an important regulator of the vitagene network.

\section{Sparing Effects of Carnitine on Vitamin E}

It is well known that vitamin $\mathrm{E}$ is main chain-breaking antioxidant in biological membranes having a unique role in the antioxidant systems $[99,100]$. In particular, vitamin E recycling mechanisms are considered to be the most important part of vitamin E efficacy in antioxidant defences. Indeed, when all essential elements of vitamin E recycling are present together with other antioxidant mechanisms, even low vitamin E levels in membranes, for example, in brain, can be sufficient to effectively protect the tissue against lipid peroxidation [99-101]. It seems likely that as a part of the antioxidant systems carnitine can have a sparing effect on vitamin E absorption and assimilation. For example, dietary LC (150 mg/ $\mathrm{kg}$ diet) increased the rates and amounts of lymphatic absorption of $\alpha$-tocopherol and fat in ovariectomized rats [102] and enhanced liver $\alpha$-tocopherol in aging ovariectomized rats [103]. Similarly, carnitine dietary supplementation decreased lipid peroxidation and promotes increased concentrations of retinol and $\alpha$-tocopherol in free-living women [104]. Furthermore, administration of LC (1.5 g/L with drinking water) to rats intoxicated with ethanol significantly decreased lipids and proteins oxidation in the serum and liver and the level of vitamin E was increased by about $20 \%$ in the liver and blood serum in comparison to the ethanol group [105]. In the irradiated rats treated with LC $1.5 \mathrm{mg} / \mathrm{kg}$ b.w, i.p. concentrations of vitamins E were higher than in those rats that were only exposed to $2.45-\mathrm{GHz}$ radiation [106]. Furthermore, metabolomics analysis shows that $\alpha$-tocopherol deficiency in rats was associated with a compensatory increase in carnitine content in the liver [107]. Therefore, molecular mechanisms of carnitine-vitamin E interactions need further investigation, but the effect of such interactions on the total antioxidant systems of the body could be quite significant. 


\section{Carnitine as a Part of Antioxidant Mixtures}

Based on the concept of integrated antioxidant systems in the body it is obvious that dietary supplementation of synergistic mixtures of various antioxidants could have higher protective effects in comparison with individual antioxidants, including carnitine. Indeed, it is the case in biological systems. For example, LC and vitamin E in combination are shown to be effective in ameliorating ochratoxin A-altered hematological and serum biochemical parameters in White Leghorn cockerels [108]. A combination of LC and vitamin C was shown to decrease the risk of ischemia-induced necrosis in damaged tissues in rats [109]. Similarly, supplementation of vitamin E, vitamin $\mathrm{C}$, and LC in combination can attenuate the oxidative stress associated with intermittent hypobaric hypoxia in rats [110]. There are a number of studies showing antioxidant protective effects of carnitine in combination with another mitochondria-related antioxidant, namely lipoic acid [111-119]. Similarly, a more complex antioxidant mixture, containing CoQ, LC, $\alpha$-tocopherol and selenium was effective in decreasing DNA damage in the liver of fumonisin B1-treated rats [120]. Furthermore, a synergistic combination of ALC, folate and vitamin $\mathrm{E}$ provided a protection against oxidative stress resulting from exposure of human neuroblastoma cells to amyloid-beta [121]. In this system, vitamin $\mathrm{E}$ prevents de novo membrane oxidative damage, folate maintains levels of the endogenous antioxidant GSH and ALC prevents A-beta-induced mitochondrial damage and ATP depletion providing superior protection to that derived from each agent alone [121]. Supplementation of pregnant and lactating sow diet with carnitine-containing bioactive substances (a blend of flax seed, rapeseed, linden inflorescence, taurine, LC and tocopherol acetate) improved maturation of the small intestinal epithelium in their offspring during the early postnatal period [122]. Recently, it has been demonstrated that ALC, L- $\alpha$-lipoic acid and silymarin had similar antioxidant effects in cisplatin-induced myocardial injury [123]. It would be advisable to assess antioxidant effects of a combination of carnitine and silymarin taking into account that both are considered to be hepatoprotectors and both are characterised by antioxidant properties [90]. In fact, it is proven that the therapeutic effect of silymarin combined with LC on non-alcoholic fatty liver disease in patients was higher than in silymarin used alone [124].

From the data presented above it is clear that the development of carnitine-containing antioxidant mixtures could be considered as an important step in stress prevention and treatment of stressed livestock animals.

\section{Specific Protective Effects of Carnitine in Poultry Production}

Based on the aforementioned data it is clear that protective effects of carnitine and its derivatives are most pronounced in various stress conditions. Indeed, by decreasing negative consequences of stresses carnitine can improve productive and reproductive performance and general health of growing chickens, parent stock, and commercial layers $[125,126]$.

\section{Stresses in poultry production}

From a physiological point of view stress is related to deviation from optimal internal and external conditions causing disturbances in homeostasis. In poultry and pig industry, there are three major types of stress: environmental, nutritional, and internal stresses [127]. Environmental stresses started from the moment when egg is laid, since temperature variation could cause embryo to start developing (high environmental temperature) or die (low temperature or fast temperature changes). Furthermore, hatchability of fertile eggs declines with length of storage and there is increase in percentages of early and late embryonic mortality with length of storage period $[128,129]$ and most likely this could affect epigenetic mechanisms determining chicken growth and development in later life. Additional time in hatchery during hatching is also a stress causing detrimental changes in antioxidant defences of the chick [130]. High environmental temperature is shown to be one of the most serious factors adversely affecting the laying performance in poultry. Egg production [131,132], egg weight [132-135], eggshell thickness [131,135-137], eggshell percentage [135], eggshell density [131], and eggshell breakage [136] were negatively affected by high ambient temperature stress. Elevated temperatures are also shown to increase mortality in both layers [133] and broilers [138]. Furthermore, the gastrointestinal tract is particularly sensitive to various stressors, which can cause a variety of changes, including alteration of the normal, protective microbiota [139] and decreased integrity of the intestinal epithelium [138]. Furthermore, heat stress is proven to inhibit the activity of digestive enzymes and reduce absorption and immune functions of intestinal mucosa [140]. The calbindin concentration was prominently decreased in ileum, cecum, colon, and eggshell gland under heat stress conditions which could be related to the deterioration of eggshell quality characteristics under heat stress conditions [135]. Broilers subjected to the heat stress were found to be characterised by reduced average daily gain and feed intake; lower viable counts of Lactobacillus and Bifidobacterium and increased viable counts of coliforms and Clostridium in small intestinal contents; shorter jejunal villus height, deeper crypt depth, and lower ratio of villus height to crypt depth [141].

The chick placement is also stressful time and the first $24 \mathrm{~h}$ of the chick's life are the most important [142]. It is believed that a chick should have an access to the feed and water as soon as possible after hatching to stimulate the development of the digestive and immune systems. It is important to mention that exposure to some stressors early in life can enhance the chicks' ability to cope with the same or with different stressors later. Indeed, compensatory responses occurred as the result of short-term exposure to stressors [143].

The increased lipid peroxidation and reduced activities of antioxidant enzymes in healthy chickens reared under unfavourable conditions including increased air temperature and humidity, high ammonia concentrations, and reduced light intensity were related to an induced oxidative stress [144]. It seems likely that vaccinations also cause substantial stress. Furthermore, it is generally assumed by immunologists that providing immunological defences is costly in terms of necessitating trade-offs with other nutrient-demanding processes such as growth, reproduction, and thermoregulation [145]. In particular, lipopolysaccharide injection decreased feed intake and body weight gain [146] and reduced ileal protein digestibility [147]. It is important to take into account that efficacy of vaccination is very much dependent on the immunocompetence of the birds, which could be compromised in stress conditions [99] and there is a range of immunosuppressive diseases in poultry, including bursal 
disease, infectious chicken anemia and Marek's disease [148,149]. High stocking densities have been shown to be another stressful condition [150] causing decreased performance, increased mortality and prevalence of leg weakness and affecting the carcass quality of broiler chickens [151]. Transferring chickens from rearing to breeder houses is always associated with increased stress and sometimes causing feather picking and cannibalism [152]. The biggest stress for commercial layers and breeders comes at the peak of egg production. Indeed, major compounds of the egg yolk are synthesised in the liver, which is working to its maximum ability and any stress can cause a drop in egg production which very often is not coming up after the stress is removed. It is well appreciated in poultry industry that egg shell quality during the second part of egg laying is a problem, especially when layer age is past 80 weeks [153]. Indeed, most losses are related to the poor shell quality of eggs produced at the end of the production cycle. For example, Grobas et al. found that the percentage of broken eggs from Brown egg-laying hens on the farm increased from $0.43 \%$ at 22 weeks to $1.81 \%$ at 74 weeks of age [154].

Microbial and virus challenges are considered to be the main internal stresses causing detrimental consequences for productive and reproductive parameters of birds [99]. Furthermore, mycotoxins are considered to be among major feed-related stressors in poultry production [155-158] and they can cause oxidative stress and immunosuppression [159-166]. In general, all the aforementioned stresses suppress reproductive performance of breeders including reduced fertility and hatchability. Furthermore, stresses are associated with impaired feed conversion, reduced average daily weight gain and increased mortality in growing birds. The immune system is most likely to be the most sensitive to various stresses $[127,149,159,167]$. In fact, stress-related dysfunction of the immune system weakens natural resistance to diseases [168] and reduces efficacy of vaccinations [169] leading to significant losses in profits.

It is generally accepted that increased free radical production is the major molecular mechanism of the negative consequences of various stresses in human life and animal/poultry production and by decreasing ROS production or improving antioxidant protection, it is possible to decrease negative consequences of various stresses $[1,2,90,99,127,170,171]$.

\section{Protective effects of carnitine in stress conditions}

Immunity: There is a substantial body of evidence indicating that LC dietary supplementation has immunomodulating effects on humoral and cell mediated immunity in chickens. For example, dietary LC supplementation ( $100 \mathrm{mg} / \mathrm{kg}$ diet) appeared to be beneficial for chickens in enhancing specific humoral responses on vaccination indicative by prevention of apoptotic death of B lymphocytes and enhanced IgG production in chickens, after both the primary and the secondary immunization [172]. In fact, a long-lasting increased IgG response due to dietary LC supplementation may be of major practical importance in the enhancement of protective immunity on vaccination. Similarly, enhanced specific antibody response to bovine serum albumin in pigeons due to LC supplementation $(1 \mathrm{~g} / \mathrm{L}$ drinking water) was observed [173]. In fact, both BSA-specific IgG and IgM responses were enhanced by about $10 \%$ by LC supplementation. The effects of supplementing Leghorn-type chickens with dietary LC (1g/ $\mathrm{kg}$ diet) after hatching for 4 weeks were assessed in a 12-week study
[174]. It was concluded, that a short-term supply of dietary LC to a conventional commercial feed after hatching enhanced subsequent humoral immunity in Leghorn-type chickens. Indeed, an increased relative thymus weight and an enhanced serum primary antibody response to a mitogen in LC-fed birds were detected. Furthermore, LC in the diet of broiler chickens $(100 \mathrm{mg} / \mathrm{kg}$ diet $)$ can enhance or advance the acute phase protein response [175]. Indeed, after a LPS challenge of male broiler chickens the elevations in circulating hemopexin and alpha-1 acid glycoprotein levels were more pronounced in the LC supplemented chickens than in control birds. In ascites-susceptible broilers serum IgG content was improved by LC supplementation $(75-100 \mathrm{mg} / \mathrm{kg}$ diet $)$ [176]. Adding LC $(300 \mathrm{mg} / \mathrm{kg}$ diet) into the chicken diet had a significant effect on Newcastle disease antibody titre at day 32 [177]. It seems likely that a combination of LC and methionine can also improve humoral immunity. Indeed, highest levels of IgG and WBC were found in birds fed 130\% NRC methionine $+150 \mathrm{mg} / \mathrm{kg}$ LC [178]. Supplementation of LC (200 mg/ $\mathrm{kg}$ ) to broiler chickens reared at high altitude increased plasma nitric oxide and immune responsiveness, which manifested in an increased toe-web thickness index measured at $24 \mathrm{~h}$ following the injection of phytohemagglutinin, an in vivo indicator of cell-mediated immune responses [179]. Furthermore, supplemental LC (100-400 mg/kg diet) enhanced the humoral and cell mediated immune responses in Japanese quail as evidenced with better antibody titres against Newcastle disease virus and greater wing web swelling in response to PHA-L injection, respectively [180]. Indeed, carnitine can have beneficial impact on chicken immunity participating in preventing infection in commercial poultry production.

Immunomodulating properties of carnitine were also shown in farm and laboratory animals. For example, in pigs, white blood cell and lymphocyte concentrations were increased by LC dietary supplementation $(250 \mathrm{mg} / \mathrm{kg}$ diet) for 10 -weeks [181]. There is also evidence that LC can improve innate immunity by modulating macrophage and neutrophil activities. For example, treatment with LC $(300 \mathrm{mg} / \mathrm{kg}$ b.w) significantly improved neutrophil functions, delayed-type hypersensitivity responses and the concentrations of immunoglobulins A and G in aged rats [182]. LC is also capable of restoring the age-related changes of neutrophil functions. Indeed, the neutrophils of aged rats exhibited an increase in superoxide anion production and decline in phagocytosis and chemotaxis when compared with that in young rat neutrophils. Superoxide anion production in aged rats was significantly decreased by LC treatment ( $50 \mathrm{mg} / \mathrm{kg}$ b.w for 30 days) which was accompanied with a significant enhancement of chemotactic and phagocytic activities which were restored to control levels $[183,184]$. It has been shown that LC restored lymphocyte proliferative response and the lytic activity of macrophages in aged rats [185-187]. In cultured mouse hybridoma cells LC is reported to stimulate growth and antibody production [188], while in leukemic cells isovaleryl carnitine improved phagocytosis and cell killing activity [189].

Carnitine was shown to regulate immune response in various inflammation-related diseases in animal models and in humans. For example, in rodents, treatment with LC $(50-100 \mathrm{mg} / \mathrm{kg}$ body weight) markedly suppressed the LPS-induced cytokine production, improving their survival during cachexia and septic shock [190,191]. Moreover LC (200 mg/kg b.w, i.p.) was reported to improve immune 
responses in mice exposed to low frequency high intensity magnetic field [192]. In vivo, protection from trinitrobenzene sulphonic acid colitis was observed in LC-treated mice and was attributed to the abrogation of both innate and adaptive immune responses [193]. Indeed, LC has been shown to reduce CD4+ and CD8+ T cell numbers and IL-2 production in splenocytes isolated from LCtreated mice [194] and reduce TNF- $\alpha$ production in Staphylococcus aureus-stimulated human polymorphonuclear cells [195]. Decreased serum TNFa levels have been reported after LC supplementation in surgical patients and AIDS patients [196,197]. LC administration was shown to ameliorate effects of LPS on cellular and humoral immunity in testis through reduction of IL-2 and by buffering the oxidative stress-induced damage [198].

It seems likely that an anti-apoptotic action of carnitine is of great importance in its immunomodulating properties. For example, it was shown that LC inhibited apoptosis of white blood cells [199] and CD4+ and CD8+ cells [197,200]. Similarly, supplementation with a carnitine-containing formula (alpha-tocopherol, alpha-lipoic acid, coenzyme Q (10), carnitine, and selenomethionine) to healthy individuals was shown to modulate the process of apoptosis under in vivo conditions [201]. Interestingly, LC and its derivatives have been shown to reduce apoptosis through the mitochondrial pathway $[202,203]$ and this appears to be linked with downregulating the transduction of the pro-apoptotic Fas signal and suppressing the generation of ceramide, an important endogenous mediator of apoptosis [204]. This anti-apoptotic effect of carnitine has been observed in different cells and organelles, including neurons [205], cardiomyocytes [206], hepatocytes [207], bone marrow cells [208], neuroblastoma cell line [209], retinal ganglion cells [210], renal tubular cells [46], embryonic neural stem cells [211], spinal cord and mitochondria [212]. Therefore, LC-mediated cytoprotection and immunomodulating properties are due, in part, to inhibition of the mitochondrial apoptotic pathway [213]

Gut immunity plays an important role in protection against various pathogens [171]. It seems likely that LC may re-establish equilibrium between pro-inflammatory and anti-inflammatory cytokines, reducing the former and/or increasing the latter. This action is extremely important in the gut, since the interplay between both innate and adaptive immune responses is crucial to perpetuate inflammation in the gut in various stress conditions. Indeed, LC can suppress DC and macrophage co-stimulatory molecule expression dose-dependently [193]. Therefore, there is a therapeutic potential of LC in treating the acute and chronic aspects of intestinal inflammation. It was shown that carnitine deficiency resulted in the hyperactivation of CD4+ T cells and enhanced production of the classical Th1 cytokine, IFN- $\gamma$ [193] and leads to increased apoptosis of enterocytes, villous atrophy, inflammation and gut injury [214]. Similarly, mice deficient in the carnitine transporter, OCTN2, develop spontaneous atrophy of intestinal epithelial cells and colonic inflammation [215]. In contrast, LC treatment significantly inhibited both APC and CD4+ T cell function, as assessed by the expression of classical activation markers, proliferation and cytokine production [193]. Indeed, LC has a protective effect on the intestinal mucosa by preventing ROS production [171].

However, the role of LC on immunological functions in various stress conditions still remains to be explored and the precise mechanisms of immunomodulating action of LC remain elusive. However, there are a number of potential mechanisms, which may be related to this effect. It is well recognised that sophisticated antioxidant defences directly and indirectly protect the host against the damaging effects of cytokines and oxidants. In particular, indirect protection is afforded by antioxidants, which reduce activation of NF- $k B$, thereby preventing up-regulation of cytokine production by oxidants. On the other hand, cytokines increase both oxidant production and antioxidant defences, thus minimising damage to the host. Antioxidants prevent oxidative stress-induced damage to immune cells. It is necessary to take into account that cellular integrity is very important for receiving, and responding to the messages needed to coordinate an immune response. The immune system generates ROS as part of its defence function and these ROS are an important weapon to kill pathogens. However, chronic overproduction of ROS can cause damage to immune cells and compromise their function [216]. In fact immune cells are rich in PUFAs which are very susceptible to free radical attack. It is well recognised that many immunological functions are membrane-dependent. These are antigen recognition, receptor expression, secretion of antibodies and cytokines, lymphocyte transformation, and contact cell lysis [216]. In particular, the receptors are important for antigen recognition and the secretion of various chemical mediators such as interferon, tumor necrosis factor, prostaglandins and interleukins. Therefore, lipid peroxidation can change membrane structure and properties (e.g. fluidity, permeability, flexibility etc.) which would affect immune cell functions. In contrast, antioxidants are able to prevent those damaging effects of ROS and maintain immune function.

If immune system is considered as "an army" fighting against invaders (microorganisms, viruses, etc.) then one would expect them to have something like mobile phones to receive and send signals to each other. Remarkably enough, major immune cells (macrophages, neutrophils, T- and B-lymphocytes) have on their surface something like "mobile phones" called receptors. Those receptors are extremely sensitive to communicating molecules, but they are also sensitive to free radicals and can be easily damaged $[99,127]$. In such a situation without proper communication all those huge armies of immune cells would become useless. They also can start fighting each other as well and eventually destroying immunocompetence and causing autoimmune reactions. If immune cells are considered as "soldiers" using chemical weapon to kill enemy, than special ammunition protecting them from their own weapon would be a crucial for effective battle. In the case of immune cells such ammunition is represented by natural antioxidants. Indeed if not properly protected, macrophage functions could be compromised including initial overproduction of free radicals with consecutive damages to specific enzymatic systems resulting in decreasing efficiency of oxidative burst and apoptosis. Based on the presented model it is clear that antioxidant defence is a crucial factor of immune defence in the body. Indeed, the crucial role of various receptors in immunocompetence processes and receptor sensitivity to ROS need further investigation, since exact biological/ biochemical mechanisms by which oxidants/antioxidants regulate immunity are still ill-defined. In particular, recent data have shown that TCR-induced ROS generation may be an important regulator of $\mathrm{T}$ cell signal transduction and gene expression [217]. Data on 
the redox dependence of signal transduction in T cells are quickly growing. Recent data suggest an underlying regulatory role for ROS in controlling the susceptibility of T cells to apoptosis [218] and innate immunity efficacy [219]. In particular, recently it has been shown that mitochondria-dependent signaling controls innate and adaptive immune responses [220]. Clearly, oxidative stress leads to accrual of damaged/misfolded proteins, lipids and causes inflammation [127].

It is important to mention that individual cells and multicellular organisms have developed intricate effective mechanisms to utilize ROS and RNS to modulate homeostasis and respond to threats. Therefore, ROS and RNS are active participants in innate and acquired immune responses. Antioxidant nutrients such as carnitine may protect against oxidant-mediated inflammation and tissue damage by virtue of their ability to upregulate the antioxidant defences and optimise redox signaling, including activation of $\mathrm{Nrf} 2$ and prevention of the activation of NF- $k \mathrm{~B}$. In fact, NF- $k \mathrm{~B}$ is required for maximal transcription of many inflammatory cytokines and adhesion molecules [221]. Therefore, LC may have great anti-inflammatory properties via downregulation of TNF- $\alpha$ and inhibition of NF- $\kappa B$. Thus, maintaining adequate antioxidant status may provide a useful approach in attenuating the cellular injury and dysfunction observed in some inflammatory disorders [222]. It is necessary to underline that, non-toxic concentrations of ROS and RNS play an important role in regulating the expression of genes involved in the inflammatory response and in modulating apoptosis [223]. At the same time, an immune response requires extensive communication between a wide range of cell types [224] and special cell receptors are of great importance in this communication. Therefore, protective effect of antioxidants, including carnitine, in prevention of membrane and receptor damages due to peroxidation could provide an important way of enhancing the immune system.

In addition to the aforementioned mechanisms of immunomodulating properties of carnitine evidence from both animal and human studies suggests that, at pharmacological doses, LC may mimic some of the actions of glucocorticoids, including their well-known immunomodulatory effect. Indeed, LC can activate glucocorticoid receptor- $\alpha(\mathrm{GR} \alpha)$ and, through this mechanism, regulate glucocorticoid-responsive genes, potentially sharing some of the biological and therapeutic properties of glucocorticoids [225]. In fact, LC reduced the binding capacity of GRa, induced its nuclear translocation, and stimulated its transcriptional activity. Moreover, LC suppressed TNFa and IL-12 release from human monocytes in glucocorticoid-like fashion [226]. It was suggested that LC is a "nutritional modulator" of the GR, by acting as an agonist-like compound [227]. While the above data suggest immunomodulating and anti-inflammatory roles for LC, some early studies have been reported contradictory results, in part reflecting the complexity of the immune response and great variation between experimental conditions [228-230].

Therefore, LC is shown to enhance immunocompetence of birds by improving humoral and cell-mediated immunity. Furthermore, LC can decrease negative consequences of post-vaccination stress and increase vaccination success and clearly effects of carnitine on innate and acquired immunity in avian species awaits further investigation.

Ascites: Ascites syndrome (pulmonary hypertension syndrome,
PHS) is a serious metabolic disease causing important economic losses to the poultry meat industry. It seems likely that interactions of genetic, physiological, environmental, and management factors are responsible for this syndrome [231]. Furthermore, it is proven that the elevated ROS production and compromised antioxidant defences are involved in the development of ascites [232-234]. Therefore, protective effects of nutritional antioxidants are of great importance $[235,236]$.

In this respect, based on results showing positive effects of LC dietary supplementation on growing chickens at various temperature regimes, Buyse et al. suggested that LC is a potential agent for reducing the incidence of metabolic diseases in broiler chickens [237]. Indeed, LC (75 or $150 \mathrm{mg} / \mathrm{kg}$ ) or LC+CoQ10 dietary supplementation increased SOD activity and reduce ascites mortality of broilers [238]. Similarly, supplemental LC (100 mg/kg diet) reduced plasma MDA, increased SOD, inhibited remodelling and postponed the occurrence of PHS for 1 week in cold-exposed broilers [239]. Indeed, in broilers reared under low temperature environment dietary LC supplementation (100 $\mathrm{mg} / \mathrm{kg}$ ) reduced organ index, enhanced antioxidative capacity of the heart (SOD and GSH-Px), and enhanced liver enzymes activity involved in tricarboxylic acid cycle, and reduced serum glucose and triglyceride [240]. Dietary LC (50-150 $\mathrm{mg} / \mathrm{kg}$ diet) improves pulmonary hypertensive response in broiler chickens subjected to hypobaric hypoxia and reduces ascites mortality in broiler chickens by increased NO production, reduced MDA concentration, and reduced right ventricular hypertrophy [241]. Supplementation of LC (200 mg/kg diet) had also beneficial effects on preventing lipid peroxidation and pulmonary hypertension in broiler chickens raised at high altitude ( $2100 \mathrm{~m}$ above sea level) [179]. Furthermore, dietary LC supplementation (100 mg/kg diet) of reduced-protein diets had beneficial effects in preventing pulmonary arterial hypertension mortality mainly through enhancing blood NO concentration [242]. Clearly, LC supplementation can be used to decrease detrimental consequences of ascites.

Other commercially relevant stresses: The reduction of heat production in exercising pigeons after LC supplementation [243] could be very relevant for protective effect of carnitine in heatstressed animals/birds. For example, LC supplementation with drinking water significantly prevented deterioration of some egg quality characteristics (relative albumen weight and height) of layers under high environmental temperature [244]. It was also shown that dietary supplemental LC (50 mg/kg diet) or LC + ascorbic acid had positive effects on body weight gain and carcass weight under high temperature conditions [245].

LC $(1 \mathrm{~g} / \mathrm{kg}$ diet $)$ or its combination with vitamin E $(200 \mathrm{mg} / \mathrm{kg}$ diet) ameliorated ochratoxin A-induced alterations in haematological and serum biochemical parameters [108]. LC dietary supplementation (400 mg/kg diet) also has a protective effect on lipid peroxidation and drop in performance of laying hens fed high cupper diet [246]. Carnitine can also help with stresses associated with chicken placement and their first days of life. For example, Nouboukpo et al. supplemented LC in drinking water $(30-60 \mathrm{mg} / \mathrm{L})$ to broiler chickens and observed improved growth rate for the first 7 days of rearing [247]. Indeed, recent data indicate that ALC supplementation at low levels (50 or $100 \mathrm{mg} / \mathrm{kg}$ ) improved antioxidative ability (increased total 
antioxidant capacity and SOD and GSH-Px activities and decreased levels of MDA in serum and liver of birds), energy metabolism, and lipid metabolism in broilers [248]. There were also synergistic effects of the combined supplementation of ALC and another antioxidant, namely lipoic acid, indicative by serum and liver SOD activities and serum glucose and TG levels [248]. Carnitine can also help with agerelated stresses in poultry. For example, LC supplementation (50-500 $\mathrm{mg} / \mathrm{kg}$ diet) of a practical layer diet of old (65-week-old) laying hens kept in cages for 8 weeks improved egg white quality indicative by increased Haugh units [249].

\section{From Understanding Molecular Mechanisms of Carnitine Action to the Development of Anti-Stress Compositions}

Taking into account the aforementioned data on antioxidant action of carnitine and results of our recent research $[1,2,90,99,100,127,170,171]$ it is clear that in order to deal with commercially-relevant stresses in poultry and pig production it is necessary to improve their adaptive ability to stresses. For this purpose, it would be desirable to develop a carnitine-containing products meeting at least five important requirements [1]:

1. Vitagene activation and redox-signaling (carnitine, betaine, vitamins $\mathrm{A}, \mathrm{E}, \mathrm{D}, \mathrm{C}, \mathrm{Se}, \mathrm{Zn}, \mathrm{Mn}$, silymarin and possibly other phytochemicals);

2. Maintenance of the vitamin E recycling system (vitamin C, Se, Vitamin $\mathrm{B}_{1}$ and $\mathrm{B}_{2}$ );

3. Provision of nutrients required for carnitine synthesis (lysine and methionine, ascorbic acid, vitamin $\mathrm{B}_{6}$ and niacin);

4. Supporting the liver, a main site of T-2 toxin, ochratoxins, fumonisins, and aflatoxins detoxification and gut, responsible for DON detoxification (vitamins $\mathrm{E}$ and $\mathrm{C}$, selenium, carnitine, betaine, organic acids, methionine and lysine);

5. Design of the immunomodulating mixture (vitamins A,E, D, $\mathrm{C}$, carnitine, Se, $\mathrm{Zn}$ and $\mathrm{Mn}$ ).

It seems likely that there should be a range of products developed to accommodate all the aforementioned requirements. In commercial conditions inclusion of various anti-stress protective compounds into the diet of pigs and poultry is complicated and difficult to implement. Firstly, a decreased feed consumption at time of stress can be observed. Secondly, such an approach has a low flexibility, since existing feeding systems do not allow to include anything into the feed loaded into the feed storage bins (usually several tons of feed for several days feeding). Therefore, before the previous feed is consumed, it is almost impossible to add anything to the feed. However, in commercial conditions there are situations when it is necessary to supplement animals/poultry with specific additives very quickly to deal with consequences of unexpected stresses (e.g. mycotoxins in the feed, immunosuppression, high temperature, etc.). In such a case water-soluble additive supplementation via drinking system is a valuable option. In fact, modern commercial poultry and pig houses are equipped with water medication systems, which can be effectively used for the aforementioned supplementations. For example, an attempt to address the aforementioned option was implemented in a commercial product PerforMax, containing a synergistic mixture of
28 compounds, including carnitine, vitamins, minerals, betaine and amino acids and supplied via drinking water. Recently commercial options and efficacy of fighting stresses by supplying the anti-stress composition via drinking water have been reviewed [170] and prospects of its use to maintain gut health in weaned piglets and newly hatched chicks were considered [171]. Indeed, supplying the PerforMax with drinking water was shown to have protective effects in growing birds in terms of improving FCR and chicken daily weight gain $[250,251]$ as well as in adult birds: increasing egg production, eggshell quality, fertility and hatchability [170]. Therefore, decreasing detrimental consequences of stresses help maintaining chicken health, productive and reproductive performance. Therefore, the aforementioned results are the first step to go from the development of the vitagene concept to the development of commercial products addressing stress-related issues in commercial poultry and pig production. It could well be that this idea might also be realized in human nutrition. Clearly more research is needed to understand a fundamental role of vitagenes in adaptation to various stresses and use carnitine-containing antioxidant compositions to affect the vitagene network and adaptive ability of livestock animals to stresses. Indeed, it is just a matter of time before commercial products based on the vitagene concept found their way to the shelves of heathy nutrition shops and veterinary clinics.

\section{Conclusions}

There is a growing interest in the potential uses of carnitine in medical practice and animal/poultry industry. The molecular mechanisms accounting for the positive effect of LC on farm animals and poultry are not yet fully elucidated but many protective effects of LC in various stress conditions reported in literature, have been related to its antioxidant action. Based on the analysis of the recent publications it could be concluded that antioxidant actions of carnitine are associated to much extent with its role in redox signaling in the cell. Indeed, LC is shown to upregulate Nrf2 and PPARs and downregulates NF- $\mathrm{KB}$ leading to anti-apoptotic and anti-inflammation actions of carnitine. Furthermore, Nrf2 mediated synthesis of antioxidant enzymes, including SOD, GSH-Px, GR, GST and GSH, in response to carnitine supplementation could be a main driving force of antioxidant action of carnitine and its derivatives. In addition, LC and its derivatives are shown to also affect vitagene networks resulting in increased adaptive ability to stresses via additional synthesis of antioxidant-related molecules, including heat shock proteins (HO-1), upregulating sirtuins, thioredoxins and SOD. It seems likely that in biological systems in vivo the interactions of the aforementioned mechanisms provide an important place for carnitine to be a crucial part of the integrated antioxidant systems of the animal and human body. Taking into account low carnitine content in grains and poultry and pig diet formulations with limited amounts of animal proteins, carnitine requirement and possible inadequacy in commercial poultry and pig nutrition should receive more attention. Furthermore, protective roles of carnitine in stress conditions of commercial poultry and pig production, including its immunomodulating properties, are difficult to overestimate. Therefore, a development of carnitine-containing antioxidant compositions supplying via drinking water seems to be an important way forward in decreasing the detrimental consequence of various stresses in poultry and pig production. Indeed, the first steps in these 
Citation: Surai PF. Carnitine Enigma: From Antioxidant Action to Vitagene Regulation Part 2. Transcription Factors and Practical Applications. J Veter Sci Med. 2015;3(2): 17.

directions have been shown to be promising.

\section{References}

1. Surai PF (2015) Antioxidant action of carnitine: molecular mechanisms and practical applications. EC Veter Sci 2: 66-84.

2. Surai PF (2015) Carnitine enigma: from antioxidant action to vitagene regulation. Part 1. Absorption, metabolism and antioxidant activities. J Veter Sci Med 3: 14

3. Yan LJ (2014) Positive oxidative stress in aging and aging-related disease tolerance. Redox Biol 2C: 165-169.

4. Ma Q, He X (2012) Molecular basis of electrophilic and oxidative defense: promises and perils of Nrf2. Pharmacol Rev 64: 1055-1081.

5. Majzunova M, Dovinova I, Barancik M, Chan JY (2013) Redox signaling in pathophysiology of hypertension. J Biomed Sci 20: 69.

6. Song P, Zou MH (2014) Redox regulation of endothelial cell fate. Cell Mol Life Sci 71: 3219-3239.

7. Kweider N, Huppertz B, Kadyrov M, Rath W, Pufe T, et al. (2014) A possible protective role of Nrf2 in preeclampsia. Ann Anat 196: 268-277.

8. Lushchak VI (2011) Adaptive response to oxidative stress: bacteria, fungi, plants and animals. Comp Biochem Physiol C Toxicol Pharmacol 153: 175 190

9. Itoh K, Mimura J, Yamamoto M (2010) Discovery of the negative regulator of Nrf2, Keap1: a historical overview. Antioxid Redox Signal 13: 1665- 1678.

10. Ma Q (2013) Role of Nrf2 in oxidative stress and toxicity. Annu Rev Pharmacol Toxicol 53: 401-426.

11. Van der Wijst MG, Brown R, Rots MG (2014) Nrf2, the master redox switch: the Achilles' heel of ovarian cancer? Biochim Biophys Acta 1846: 494-509.

12. Itoh K, Ye P, Matsumiya T, Tanji K, Ozaki T (2015) Emerging functional cross-talk between the Keap1-Nrf2 system and mitochondria. J Clin Biochem Nutr 56: 91-97.

13. Tang W, Jiang YF, Ponnusamy M, Diallo M (2014) Role of Nrf2 in chronic liver disease. World J Gastroenterol 20: 13079-13087.

14. Howden R (2013) Nrf2 and cardiovascular defense. Oxid Med Cell Longev 2013: 104308

15. Vriend J, Reiter RJ (2015) The Keap1-Nrf2-antioxidant response element pathway: a review of its regulation by melatonin and the proteasome. Mo Cell Endocrinol 401: 213-220.

16. Keum YS, Choi BY (2014) Molecular and chemical regulation of the Keap1Nrf2 signaling pathway. Molecules 19: 10074-10089.

17. Choi BH, Kang KS, Kwak MK (2014) Effect of redox modulating NRF2 activators on chronic kidney disease. Molecules 19: 12727-12759.

18. Bhakkiyalakshmi E, Sireesh D, Rajaguru P, Paulmurugan R, Ramkumar KM (2015) The emerging role of redox-sensitive Nrf2-Keap1 pathway in diabetes. Pharmacol Res 91: 104-114.

19. Lee BH, Hsu WH, Hsu YW, Pan TM (2013) Dimerumic acid attenuates receptor for advanced glycation endproducts signal to inhibit inflammation and diabetes mediated by Nrf2 activation and promotes methylglyoxal metabolism into d-lactic acid. Free Radic Biol Med 60: 7-16.

20. Zhou S, Sun W, Zhang Z, Zheng Y (2014) The role of Nrf2-mediated pathway in cardiac remodelling and heart failure. Oxid Med Cell Longev 2014: 260429.

21. Lee JM, Calkins MJ, Chan K, Kan YW, Johnson JA (2003) Identification of the NF-E2-related factor-2-dependent genes conferring protection against oxidative stress in primary cortical astrocytes using oligonucleotide microarray analysis. J Biol Chem 278: 12029-12038.

22. Hayes JD, Dinkova-Kostova AT (2014) The Nrf2 regulatory network provides an interface between redox and intermediary metabolism. Trends Biochem Sci 39: 199-218.

23. Surh YJ (2008) NF-kappa B and Nrf2 as potential chemopreventive targets of some anti-inflammatory and antioxidative phytonutrients with antiinflammatory and antioxidative activities. Asia Pac J Clin Nutr 17 Suppl 1: 269-272.

24. Surh YJ, Kundu JK, Na HK (2008) Nrf2 as a master redox switch in turning on the cellular signaling involved in the induction of cytoprotective genes by some chemopreventive phytochemicals. Planta Med 74: 1526-1539.

25. Dayalan Naidu S, Kostov RV, Dinkova-Kostova AT (2015) Transcription factors Hsf1 and Nrf2 engage in crosstalk for cytoprotection. Trends Pharmacol Sci 36: 6-14

26. Calabrese V, Giuffrida Stella AM, Calvani M, Butterfield DA (2006) Acetylcarnitine and cellular stress response: roles in nutritional redox homeostasis and regulation of longevity genes. J Nutr Biochem 17: 73-88.

27. Shen W, Liu K, Tian C, Yang L, Li X, et al. (2008) R-alpha-lipoic acid and acetyl-L-carnitine complementarily promote mitochondrial biogenesis in murine 3T3-L1 adipocytes. Diabetologia 51: 165-174.

28. Barhwal K, Hota SK, Jain V, Prasad D, Singh SB, et al. (2009) Acetyl-Icarnitine (ALCAR) prevents hypobaric hypoxia-induced spatial memory impairment through extracellular related kinase-mediated nuclear factor erythroid 2-related factor 2 phosphorylation. Neuroscience 161: 501-514.

29. Hota KB, Hota SK, Chaurasia OP, Singh SB (2012) Acetyl-L-carnitinemediated neuroprotection during hypoxia is attributed to ERK1/2-Nrf2 regulated mitochondrial biosynthesis. Hippocampus 22: 723-736.

30. Zambrano S, Blanca AJ, Ruiz-Armenta MV, Miguel-Carrasco JL, Revilla E, et al. (2013) The renoprotective effect of L-carnitine in hypertensive rats is mediated by modulation of oxidative stress-related gene expression. Eur $\mathrm{J}$ Nutr 52: 1649-1659.

31. Kui L, Jian-gang G, Yan-bo S, Si-chuan H (2012) The antioxidation of L-carnitine on renal ischemia-reperfusion injury and its underlying mechanism. J Modern Urology 3: R965.

32. Yang SP, Yang XZ, Cao GP (2015) Acetyl---carnitine prevents homocysteineinduced suppression of Nrf2/Keap1 mediated antioxidation in human lens epithelial cells. Mol Med Rep 12: 1145-1150.

33. Tkach KE, Oyler JE, Altan-Bonnet G (2014) Cracking the NF-KB code. Sc Signal 7: pe5

34. Buelna-Chontal M, Zazueta C (2013) Redox activation of Nrf2 \& NF-kB: a double end sword? Cell Signal 25: 2548-2557.

35. Pedruzzi LM, Stockler-Pinto MB, Leite M Jr, Mafra D (2012) Nrf2-keap1 system versus NF-kB: the good and the evil in chronic kidney disease? Biochimie 94: 2461-2466.

36. Pal S, Bhattacharjee A, Ali A, Mandal NC, Mandal SC, et al. (2014) Chronic inflammation and cancer: potential chemoprevention through nuclear factor kappa B and p53 mutual antagonism. J Inflamm (Lond) 11: 23.

37. Hayden MS, Ghosh S (2014) Regulation of NF-KB by TNF family cytokines Semin Immunol 26: 253-266.

38. Grilli M, Memo M (1997) Transcriptional pharmacology of neurodegenerative disorders: novel venue towards neuroprotection against excitotoxicity? Mol Psychiatry 2: 192-194.

39. Chiechio S, Copani A, De Petris L, Morales MEP, Nicoletti F, et al. (2006) Transcriptional regulation of metabotropic glutamate receptor $2 / 3$ expression by the NF-kappaB pathway in primary dorsal root ganglia neurons: a possible mechanism for the analgesic effect of L-acetylcarnitine. Mol Pain 2: 20.

40. Cuccurazzu B, Bortolotto V, Valente MM, Ubezio F, Koverech A, et al. (2013) Upregulation of mGlu2 receptors via NF-kB p65 acetylation is involved in the Proneurogenic and antidepressant effects of acetyl-L-carnitine. Neuropsychopharmacology 38: 2220-2230.

41. Orlandi A, Francesconi A, Marcellini M, Di Lascio A, Spagnoli LG (2007) Propionyl-L-carnitine reduces proliferation and potentiates Bax-related apoptosis of aortic intimal smooth muscle cells by modulating nuclear factorkappaB activity. J Biol Chem 282: 4932-4942.

42. Koc A, Ozkan T, Karabay AZ, Sunguroglu A, Aktan F (2011) Effect of $\mathrm{L}$-carnitine on the synthesis of nitric oxide in RAW $264 \cdot 7$ murine macrophage 
Citation: Surai PF. Carnitine Enigma: From Antioxidant Action to Vitagene Regulation Part 2. Transcription Factors and Practical Applications. J Veter Sci Med. 2015;3(2): 17.

cell line. Cell Biochem Funct 29: 679-685.

43. Miguel-Carrasco JL, Monserrat MT, Mate A, Vázquez CM (2010) Comparative effects of captopril and I-carnitine on blood pressure and antioxidant enzyme gene expression in the heart of spontaneously hypertensive rats. Eur J Pharmacol 632: 65-72

44. Zambrano S, Blanca AJ, Ruiz-Armenta MV, Miguel-Carrasco JL, Arévalo M et al. (2013) L-Carnitine protects against arterial hypertension-related cardiac fibrosis through modulation of PPAR-y expression. Biochem Pharmacol 85: 937-944.

45. Zambrano S, Blanca AJ, Ruiz-Armenta MV, Miguel-Carrasco JL, Arévalo $\mathrm{M}$, et al. (2014) L-carnitine attenuates the development of kidney fibrosis in hypertensive rats by upregulating PPAR-y. Am J Hypertens 27: 460-470.

46. Sue YM, Chou HC, Chang CC, Yang NJ, Chou Y, et al. (2014) L-carnitine protects against carboplatin-mediated renal injury: AMPK- and PPARadependent inactivation of NFAT3. PLoS One 9: e104079.

47. Kota BP, Huang TH, Roufogalis BD (2005) An overview on biological mechanisms of PPARs. Pharmacol Res 51: 85-94.

48. Berger J, Moller DE (2002) The mechanisms of action of PPARs. Annu Rev Med 53: 409-435.

49. Nakamura MT, Yudell BE, Loor JJ (2014) Regulation of energy metabolism by long-chain fatty acids. Prog Lipid Res 53: 124-144.

50. Berger JP, Akiyama TE, Meinke PT (2005) PPARs: therapeutic targets for metabolic disease. Trends Pharmacol Sci 26: 244-251.

51. Neels JG, Grimaldi PA (2014) Physiological functions of peroxisome proliferator-activated receptor $\beta$. Physiol Rev 94: 795-858.

52. Juge-Aubry CE, Hammar E, Siegrist-Kaiser C, Pernin A, Takeshita A, et al (1999) Regulation of the transcriptional activity of the peroxisome proliferator activated receptor alpha by phosphorylation of a ligand-independent transactivating domain. J Biol Chem 274: 10505-10510.

53. Fan W, Evans R (2015) PPARs and ERRs: molecular mediators of mitochondrial metabolism. Curr Opin Cell Biol 33: 49-54.

54. Zhang S, Gu H, Hu N (2015) Role of peroxisome proliferator-activated receptor $\mathrm{y}$ in ocular diseases. J Ophthalmol 2015: 275435.

55. Giordano Attianese GM, Desvergne B (2015) Integrative and systemic approaches for evaluating PPAR $\beta / \delta$ (PPARD) function. Nucl Recept Signal 13: e001.

56. Ndisang JF (2014) Cross-talk between heme oxygenase and peroxisome proliferator-activated receptors in the regulation of physiological functions. Front Biosci (Landmark Ed) 19: 916-935

57. Musso G, Gambino R, Cassader M (2010) Non-alcoholic fatty liver disease from pathogenesis to management: an update. Obes Rev 11: 430-445.

58. Zhou T, Yan X, Wang G, Liu H, Gan X, et al. (2015) Evolutionary pattern and regulation analysis to support why diversity functions existed within PPAR gene family members. Biomed Res Int 2015: 613910.

59. Kim T, Yang Q (2013) Peroxisome-proliferator-activated receptors regulate redox signaling in the cardiovascular system. World J Cardiol 5: 164-174.

60. Khoo NK, Hebbar S, Zhao W, Moore SA, Domann FE, et al. (2013) Differential activation of catalase expression and activity by PPAR agonists: implications for astrocyte protection in anti-glioma therapy. Redox Biol 1: 70-79.

61. Liu X, Jang SS, An Z, Song H, Kim WD, et al. (2012) Fenofibrate decreases radiation sensitivity via peroxisome proliferator-activated receptor $\alpha$-mediated superoxide dismutase induction in HeLa cells. Radiat Oncol J 30: 88-95.

62. Li JL, Wang QY, Luan HY, Kang ZC, Wang CB (2012) Effects of L-carnitine against oxidative stress in human hepatocytes: involvement of peroxisome proliferator-activated receptor alpha. J Biomed Sci 19: 32.

63. Diep QN, Amiri F, Touyz RM, Cohn JS, Endemann D, et al. (2002) PPARalpha activator effects on Ang Il-induced vascular oxidative stress and inflammation. Hypertension 40: 866-871.

64. Kong L, Ren W, Li W, Zhao S, Mi H, et al. (2011) Activation of peroxisome proliferator activated receptor alpha ameliorates ethanol induced steatohepatitis in mice. Lipids Health Dis 10: 246

65. Ringseis R, Eder K (2009) Influence of pharmacological PPARalpha activators on carnitine homeostasis in proliferating and non-proliferating species. Pharmacol Res 60: 179-184.

66. Kienesberger K, Pordes AG, Völk TG, Hofbauer R (2014) L-carnitine and PPARa-agonist fenofibrate are involved in the regulation of Carnitine Acetyltransferase (CrAT) mRNA levels in murine liver cells. BMC Genomics 15: 514.

67. Marx N, Sukhova GK, Collins T, Libby P, Plutzky J (1999) PPARalpha activators inhibit cytokine-induced vascular cell adhesion molecule-1 expression in human endothelial cells. Circulation 99: 3125-3131.

68. Chen $\mathrm{HH}$, Sue YM, Chen $\mathrm{CH}$, Hsu YH, Hou CC, et al. (2009) Peroxisome proliferator-activated receptor alpha plays a crucial role in L-carnitine antiapoptosis effect in renal tubular cells. Nephrol Dial Transplant 24: 3042-3049.

69. Zhang Y, Yi S, Jiang F, Qiu Y, Chen H, et al. (2013) L-carnitine ameliorates colonic cancer cachexia in mice by regulating the expressions of PPARa and PPARy. Chinese J Gastroenterol 266-270.

70. Jing L, Zhou LJ, Li WM, Zhang FM, Yuan L, et al. (2011) Carnitine regulates myocardial metabolism by Peroxisome Proliferator-Activated Receptor-alpha (PPARalpha) in alcoholic cardiomyopathy. Med Sci Monit 17: BR1-BR9.

71. Jun DW, Cho WK, Jun JH, Kwon HJ, Jang KS, et al. (2011) Prevention of free fatty acid-induced hepatic lipotoxicity by carnitine via reversal of mitochondrial dysfunction. Liver Int 31: 1315-1324.

72. Montesano A, Sanesi P, Luzi L, Benedini S, Terruzzi I (2015) Potential therapeutic role of L-carnitine in skeletal muscle oxidative stress and atrophy conditions. Oxid Med Cell Longev 2015: 646171.

73. Calabrese V, Cornelius C, Mancuso C, Pennisi G, Calafato S, et al. (2008) Cellular stress response: a novel target for chemoprevention and nutritional neuroprotection in aging, neurodegenerative disorders and longevity. Neurochem Res 33: 2444-2471.

74. Rattan SI (1998) The nature of gerontogenes and vitagenes. Antiaging effects of repeated heat shock on human fibroblasts. Ann N Y Acad Sci 854: 54-60.

75. Calabrese V, Guagliano E, Sapienza M, Panebianco M, Calafato S, et al. (2007) Redox regulation of cellular stress response in aging and neurodegenerative disorders: role of vitagenes. Neurochem Res 32: 757 773 .

76. Calabrese V, Calafato S, Puleo E, Cornelius C, Sapienza M, et al. (2008) Redox regulation of cellular stress response by ferulic acid ethyl ester in human dermal fibroblasts: role of vitagenes. Clin Dermatol 26: 358-363.

77. Calabrese V, Cornelius C, Mancuso C, Barone E, Calafato S, et al. (2009) Vitagenes, dietary antioxidants and neuroprotection in neurodegenerative diseases. Front Biosci (Landmark Ed) 14: 376-397.

78. Calabrese V, Cornelius C, Dinkova-KostovaAT, Calabrese EJ (2009) Vitagenes, cellular stress response, and acetylcarnitine: relevance to hormesis. Biofactors 35: 146-160.

79. Calabrese V, Cornelius C, Stella AM, Calabrese EJ (2010) Cellular stress responses, mitostress and carnitine insufficiencies as critical determinants in aging and neurodegenerative disorders: role of hormesis and vitagenes. Neurochem Res 35: 1880-1915.

80. Calabrese V, Cornelius C, Dinkova-Kostova AT, Calabrese EJ, Mattson MP (2010) Cellular stress responses, the hormesis paradigm, and vitagenes: novel targets for therapeutic intervention in neurodegenerative disorders. Antioxid Redox Signal 13: 1763-1811.

81. Calabrese V, Cornelius C, Trovato A, Cavallaro M, Mancuso C, et al. ( 2010) The hormetic role of dietary antioxidants in free radical-related diseases. Curr Pharm Des 16: 877-883.

82. Calabrese V, Cornelius C, Cuzzocrea S, lavicoli I, Rizzarelli E, et al. (2011) Hormesis, cellular stress response and vitagenes as critical determinants in aging and longevity. Mol Aspects Med 32: 279-304. 
Citation: Surai PF. Carnitine Enigma: From Antioxidant Action to Vitagene Regulation Part 2. Transcription Factors and Practical Applications. J Veter Sci Med. 2015;3(2): 17.

83. Calabrese V, Cornelius C, Dinkova-Kostova AT, lavicoli I, Di Paola R, et al (2012) Cellular stress responses, hormetic phytochemicals and vitagenes in aging and longevity. Biochim Biophys Acta 1822: 753-783.

84. Calabrese V, Scapagnini G, Davinelli S, Koverech G, Koverech A, et al. (2014) Sex hormonal regulation and hormesis in aging and longevity: role of vitagenes. J Cell Commun Signal 8: 369-384.

85. Cornelius C, Perrotta R, Graziano A, Calabrese EJ, Calabrese V (2013) Stress responses, vitagenes and hormesis as critical determinants in aging and longevity: Mitochondria as a "chi". Immun Ageing 10: 15.

86. Cornelius C, Graziano A, Calabrese EJ, Calabrese V (2013) Hormesis and vitagenes in aging and longevity: mitochondrial control and hormonal regulation. Horm Mol Biol Clin Investig 16: 73-89.

87. Cornelius C, Koverech G, Crupi R, Di Paola R, Koverech A, et al. (2014) Osteoporosis and alzheimer pathology: Role of cellular stress response and hormetic redox signaling in aging and bone remodeling. Front Pharmacol 5 : 120.

88. Trovato Salinaro A, Cornelius C, Koverech G, Koverech A, Scuto M, et al. (2014) Cellular stress response, redox status, and vitagenes in glaucoma: a systemic oxidant disorder linked to Alzheimer's disease. Front Pharmacol 5 : 129

89. Calabrese V, Stella AM, Butterfield DA, Scapagnini G (2004) Redox regulation in neurodegeneration and longevity: role of the heme oxygenase and HSP70 systems in brain stress tolerance. Antioxid Redox Signal 6: 895-913.

90. Surai PF (2015) Silymarin as a natural antioxidant: an overview of the current evidence and perspectives. Antioxidants 4: 204-247.

91. Calabrese V, Ravagna A, Colombrita C, Scapagnini G, Guagliano E, et al. (2005) Acetylcarnitine induces heme oxygenase in rat astrocytes and protects against oxidative stress: involvement of the transcription factor Nrf2. J Neurosci Res 79: 509-521.

92. Calabrese V, Colombrita C, Sultana R, Scapagnini G, Calvani M, et al. (2006) Redox modulation of heat shock protein expression by acetylcarnitine in aging brain: relationship to antioxidant status and mitochondrial function. Antioxid Redox Signal 8: 404-416.

93. Calò LA, Pagnin E, Davis PA, Semplicini A, Nicolai R, et al. (2006) Antioxidant effect of L-carnitine and its short chain esters: relevance for the protection from oxidative stress related cardiovascular damage. Int J Cardiol 107: 54-60.

94. Calò LA, Davis PA, Pagnin E, Bertipaglia L, Naso A, et al. (2008) Carnitinemediated improved response to erythropoietin involves induction of haem oxygenase-1: studies in humans and in an animal model. Nephrol Dia Transplant 23: 890-895.

95. Abdul HM, Calabrese V, Calvani M, Butterfield DA (2006) Acetyl-L-carnitineinduced up-regulation of heat shock proteins protects cortical neurons against amyloid-beta peptide 1-42-mediated oxidative stress and neurotoxicity: implications for Alzheimer's disease. J Neurosci Res 84: 398-408.

96. Cao Y, Li X, Wang CJ, Li P, Yang B, et al. (2015) Role of NF-E2-related factor 2 in neuroprotective effect of I-carnitine against high glucose-induced oxidative stress in the retinal ganglion cells. Biomed Pharmacother 69: 345348

97. Morigi M, Perico L, Rota C, Longaretti L, Conti S, et al. (2015) Sirtuin 3-dependent mitochondrial dynamic improvements protect against acute kidney injury. J Clin Invest 125: 715-726

98. Marcovina SM, Sirtori C, Peracino A, Gheorghiade M, Borum P, et al. (2013) Translating the basic knowledge of mitochondrial functions to metabolic therapy: role of L-carnitine. Transl Res 161: 73-84

99. Surai PF (2002) Natural antioxidants in avian nutrition and reproduction. Nottingham University Press, Nottingham, UK.

100. Surai PF (2014) Polyphenol compounds in the chicken/animal diet: from the past to the future. J Anim Physiol Anim Nutr (Berl) 98: 19-31.

101. Surai PF, Noble RC, Speake BK (1996) Tissue-specific differences in antioxidant distribution and susceptibility to lipid peroxidation during development of the chick embryo. Biochim Biophys Acta 1304: 1-10.
102. Zou W, Noh SK, Owen KQ, Koo SI (2005) Dietary L-carnitine enhances the lymphatic absorption of fat and alpha-tocopherol in ovariectomized rats. $J$ Nutr 135: 753-756.

103. Clark RM, Balakrishnan A, Waters D, Aggarwal D, Owen KQ, et al. (2007) L-carnitine increases liver alpha-tocopherol and lowers liver and plasma triglycerides in aging ovariectomized rats. J Nutr Biochem 18: 623-628.

104. Sachan DS, Hongu N, Johnsen M (2005) Decreasing oxidative stress with choline and carnitine in women. J Am Coll Nutr 24: 172-176.

105. Augustyniak A, Skrzydlewska E (2009) L-Carnitine in the lipid and protein protection against ethanol-induced oxidative stress. Alcohol 43: 217-223.

106. Türker Y, Nazıroğlu M, Gümral N, Celik O, Saygın M, et al. (2011) Selenium and L-carnitine reduce oxidative stress in the heart of rat induced by 2.45 $\mathrm{GHz}$ radiation from wireless devices. Biol Trace Elem Res 143: 1640-1650.

107. Moazzami AA, Andersson R, Kamal-Eldin A (2011) Changes in the metabolic profile of rat liver after a-tocopherol deficiency as revealed by metabolomics analysis. NMR Biomed 24: 499-505.

108. Abidin Z, Khan MZ, Khatoon A, Saleemi MK, Khan A, et al. (2013) Ameliorative effects of L-carnitine and vitamin $E$ (a-tocopherol) on haematological and serum biochemical parameters in White Leghorn cockerels given ochratoxin a contaminated feed. Br Poult Sci 54: 471-477.

109. Arslan E, Basterzi Y, Aksoy A, Majka C, Unal S, et al. (2005) The additive effects of carnitine and ascorbic acid on distally burned dorsal skin flap in rats. Med Sci Monit 11: BR176-BR180.

110. Devi SA, Vani R, Subramanyam MV, Reddy SS, Jeevaratnam K (2007) Intermittent hypobaric hypoxia-induced oxidative stress in rat erythrocytes: protective effects of vitamin E, vitamin C, and carnitine. Cell Biochem Funct 25: 221-231.

111. Kumaran S, Panneerselvam KS, Shila S, Sivarajan K, Panneerselvam C (2005) Age-associated deficit of mitochondrial oxidative phosphorylation in skeletal muscle: role of carnitine and lipoic acid. Mol Cell Biochem 280: 83-89.

112. Hagen TM, Moreau R, Suh JH, Visioli F (2002) Mitochondrial decay in the aging rat heart: evidence for improvement by dietary supplementation with acetyl-L-carnitine and/or lipoic acid. Ann N Y Acad Sci 959: 491-507.

113. Hagen TM, Liu J, Lykkesfeldt J, Wehr CM, Ingersoll RT, et al. (2002) Feeding acetyl-L-carnitine and lipoic acid to old rats significantly improves metabolic function while decreasing oxidative stress. Proc Natl Acad Sci USA 99: 1870-1875.

114. McMackin CJ, Widlansky ME, Hamburg NM, Huang AL, Weller S, et al (2007) Effect of combined treatment with alpha-Lipoic acid and acetyl-Lcarnitine on vascular function and blood pressure in patients with coronary artery disease. J Clin Hypertens (Greenwich) 9: 249-255.

115. Liu J, Killilea DW, Ames BN (2002) Age-associated mitochondrial oxidative decay: improvement of carnitine acetyltransferase substrate-binding affinity and activity in brain by feeding old rat's acetyl-L- carnitine and/or R-a -lipoicacid. Proc Natl Acad Sci USA 99: 1876-1881.

116. Savitha S, Sivarajan K, Haripriya D, Kokilavani V, Panneerselvam C (2005) Efficacy of levo carnitine and alpha lipoic acid in ameliorating the decline in mitochondrial enzymes during aging. Clin Nutr 24: 794-800.

117. Savitha S, Panneerselvam C (2006) Mitochondrial membrane damage during aging process in rat heart: potential efficacy of L-carnitine and DL alpha lipoic acid. Mech Ageing Dev 127: 349-355

118. Abdul HM, Butterfield DA (2007) Involvement of PI3K/PKG/ERK1/2 signaling pathways in cortical neurons to trigger protection by cotreatment of acetyl-L-carnitine and alpha-lipoic acid against HNE-mediated oxidative stress and neurotoxicity: implications for Alzheimer's disease. Free Radic Biol Med 42: 371-384

119. Tamilselvan J, Jayaraman G, Sivarajan K, Panneerselvam C (2007) Agedependent upregulation of p53 and cytochrome c release and susceptibility to apoptosis in skeletal muscle fiber of aged rats: role of carnitine and lipoic acid. Free Radic Biol Med 43: 1656-1669. 
Citation: Surai PF. Carnitine Enigma: From Antioxidant Action to Vitagene Regulation Part 2. Transcription Factors and Practical Applications. J Veter Sci Med. 2015;3(2): 17.

120. Atroshi F, Rizzo A, Biese I, Veijalainen P, Saloniemi H, et al. (1999) Fumonisin B1-induced DNA damage in rat liver and spleen: effects of pretreatment with coenzyme Q10, L-carnitine, alpha-tocopherol and selenium. Pharmacol Res 40: 459-467.

121. Dhitavat S, Ortiz D, Rogers E, Rivera E, Shea TB (2005) Folate, vitamin $\mathrm{E}$, and acetyl-L-carnitine provide synergistic protection against oxidative stress resulting from exposure of human neuroblastoma cells to amyloidbeta. Brain Res 1061: 114-117.

122. Strzałkowski AK, Godlewski MM, Hallay N, Kulasek G, Gajewski Z, et al. (2007) The effect of supplementing sow with bioactive substances on neonatal small intestinal epithelium. J Physiol Pharmacol 58 Suppl 3: 115122

123. El-Awady el-SE, Moustafa YM, Abo-Elmatty DM, Radwan A (2011) Cisplatininduced cardiotoxicity: Mechanisms and cardioprotective strategies. Eur J Pharmacol 650: 335-341.

124. Zhen L, Hongliang S, Jianbiao Z (2006) Clinical effect of silymarin combined with levocarnitine on non-alcoholic fatty liver disease. China Mod Med 7: R575.

125. Arslan C (2006) L-Carnitine and its use as a feed additive in poultry feeding a review. Rev Méd Vét 157: 134-142.

126. Golzar Adabi SH, Cooper RG, Ceylan N, Corduk M (2011) L-carnitine and its functional effects in poultry nutrition. Worlds Poult Sci J 67: 277-295.

127. Surai PF (2006) Selenium in Nutrition and Health. Nottingham University Press, Nottingham, UK

128. Elibol O, Peak SD, Brake J (2002) Effect of flock age, length of egg storage and frequency of turning during storage on hatchability of broiler hatching eggs. Poult Sci 81: 945-950

129. Fasenko GM (2007) Egg storage and the embryo. Poult Sci 86: 1020-1024

130. Karadas F, Surai PF, Sparks NH (2011) Changes in broiler chick tissue concentrations of lipid-soluble antioxidants immediately post-hatch. Comp Biochem Physiol A Mol Integr Physiol 160: 68-71.

131. de Andrade AN, Rogler JC, Featherson WR, Allison CW (1977) Interrelationships between diet and elevated temperature (cyclic and constant) on egg production and shell quality. Poult Sci 56: 1178-1188.

132. Mack LA, Felver-Gant JN, Dennis RL, Cheng HW (2013) Genetic variation alter production and behavioral responses following heat stress in 2 strains of laying hens. Poult Sci 92: 285-294.

133. Mashaly MM, Hendricks GL 3rd, Kalama MA, Gehad AE, Abbas AO, et al. (2004) Effect of heat stress on production parameters and immune responses of commercial laying hens. Poult Sci 83: 889-894.

134. Sahin N, Onderci M, Balci TA, Cikim G, Sahin K, et al. (2007) The effect of soy isoflavones on egg quality and bone mineralisation during the late laying period of quail. Br Poult Sci 48: 363-369.

135. Ebeid TA, Suzuki T, Sugiyama T (2012) High ambient temperature influences eggshell quality and calbindin-D28k localization of eggshell gland and all intestinal segments of laying hens. Poult Sci 91: 2282-2287.

136. Lin H, Mertens K, Kemps B, Govaerts T, De Ketelaere B, et al. (2004) New approach of testing the effect of heat stress on eggshell quality: mechanical and material properties of eggshell and membrane. Br Poult Sci 45: 476482

137. Franco-Jimenez DJ, Scheideler SE, Kittok RJ, Brown-Brandl TM, Robeson LR, et al. (2007) Differential effects of heat stress in three strains of laying hens. J Appl Poult Res 16: 628-634.

138. Quinteiro-Filho WM, Ribeiro A, Ferraz-de-Paula V, Pinheiro ML, Sakai M, et al. (2010) Heat stress impairs performance parameters, induces intestinal injury, and decreases macrophage activity in broiler chickens. Poult Sci 89: 1905-1914

139. Burkholder KM, Thompson KL, Einstein ME, Applegate TJ, Patterson JA (2008) Influence of stressors on normal intestinal microbiota, intestina morphology, and susceptibility to Salmonella enteritidis colonization in broilers. Poult Sci 87: 1734-1741.
140. Chen Z, Xie J, Wang B, Tang J (2014) Effect of y-aminobutyric acid on digestive enzymes, absorption function, and immune function of intestinal mucosa in heat-stressed chicken. Poult Sci 93: 2490-2500.

141. Song J, Xiao K, Ke YL, Jiao LF, Hu CH, et al. (2014) Effect of a probiotic mixture on intestinal microflora, morphology, and barrier integrity of broilers subjected to heat stress. Poult Sci 93: 581-588.

142. Noy Y, Uni Z (2010) Early nutrition strategy. Worlds Poult Sci J 66: 639-646.

143. Johnson RW, Curtis SE, Shanks RD (1991) Effects on chick performance of ammonia and heat stressors in various combination sequences. Poult Sci 70: 1132-1137.

144. Georgieva NV, Stoyanchev K, Bozakova N, Jotova I (2011) Combined effects of muscular dystrophy, ecological stress, and selenium on blood antioxidant status in broiler chickens. Biol Trace Elem Res 142: 532-545.

145. Lochmiller RL, Deerenberg C (2000) Trade-offs in evolutionary immunology: just what is the cost of immunity? OIKOS 88: 87-98

146. Lai HT, Nieuwland MG, Kemp B, Aarnink AJ, Parmentier HK (2011) Effects of repeated intratracheally administered lipopolysaccharide on primary and secondary specific antibody responses and on body weight gain of broilers. Poult Sci 90: 337-351.

147. Yang XJ, Li WL, Feng Y, Yao JH (2011) Effects of immune stress on growth performance, immunity, and cecal microflora in chickens. Poult Sci 90 $2740-2746$

148. Fussell LW (1998) Poultry industry strategies for control of immunosuppressive diseases. Poult Sci 77: 1193-1196.

149. Hoerr FJ (2010) Clinical aspects of immunosuppression in poultry. Avian Dis 54: 2-15.

150. Puron D, Santamaria R, Segura JC, Alamilla JL (1995) Broiler performance at different stocking densities. J Appl Poult Res 4: 55-60.

151. Feddes JJ, Emmanuel EJ, Zuidhof MJ (2002) Broiler performance, body weight variance, feed and water intake, and carcass quality at different stocking densities. Poult Sci 81: 774-779.

152. Gunnarsson S, Keeling LJ, Svedberg J (1999) Effect of rearing factors on the prevalence of floor eggs, cloacal cannibalism and feather pecking in commercial flocks of loose housed laying hens. Br Poult Sci 40: 12-18.

153. Safaa HM, Serrano MP, Valencia DG, Frikha M, Jiménez-Moreno E, et al (2008) Productive performance and egg quality of brown egg-laying hens in the late phase of production as influenced by level and source of calcium in the diet. Poult Sci 87: 2043-2051.

154. Grobas S, Mendez J, De Blas C, Mateos GG (1999) Influence of dietary energy, supplemental fat and linoleic acid concentration on performance of laying hens at two ages. Br Poult Sci 40: 681-687.

155. Awad W, Ghareeb K, Böhm J, Zentek J (2013) The toxicological impacts of the Fusarium mycotoxin, deoxynivalenol, in poultry flocks with specia reference to immunotoxicity. Toxins (Basel) 5: 912-925.

156. Dhama K, Chakraborty S, Verma AK, Tiwari R, Barathidasan R, et al. (2013) Fungal/mycotic diseases of poultry-diagnosis, treatment and control: a review. Pak J Biol Sci 16: 1626-1640.

157. Rawal S, Kim JE, Coulombe R Jr (2010) Aflatoxin B1 in poultry: toxicology, metabolism and prevention. Res Vet Sci 89: 325-331.

158. Battacone G, Nudda A, Pulina G (2010) Effects of ochratoxin a on livestock production. Toxins (Basel) 2: 1796-1824.

159. Surai P, Dvorska J (2005) Effect of mycotoxins on antioxidant status and immunity. In: Diaz D (ed). The mycotoxin blue book, Nottingham University Press, Nottingham, UK, 93-137.

160. Fisinin VI, Surai PF (2012) Properties and toxicity of DON. Mycotoxins and antioxidants: Uncompromising fighting. Part 1. Animal Production of Russia (Zhivotnovodstvo Rossii) 5: 11-14.

161. Fisinin VI, Surai PF (2012) Properties and toxicity of DON. Mycotoxins and antioxidants: Uncompromising fighting. Part 2. Animal Production of Russia 
Citation: Surai PF. Carnitine Enigma: From Antioxidant Action to Vitagene Regulation Part 2. Transcription Factors and Practical Applications. J Veter Sci Med. 2015;3(2): 17.

(Zhivotnovodstvo Rossii, Russia) 6: 3-5.

162. Fisinin VI, Surai PF (2012) Mycotoxins and antioxidants: Uncompromising fighting. Ochratoxin A. Part 1. Compounded Feed (Kombikorma, Russia) 3: $55-60$.

163. Fisinin VI, Surai PF (2012) Mycotoxins and antioxidants: Uncompromising fighting. Ochratoxin A. Part 2. Compounded Feed (Kombikorma, Russia) 5: $59-60$.

164. Fisinin VI, Surai PF (2012) Mycotoxins and antioxidants: Uncompromising fighting. T-toxin - metabolism and toxicity. Part 1. Poultry and Poultry Products (Ptiza i Ptizeproducti, Russia) 3: 38-41.

165. Fisinin VI, Surai PF (2012) Mycotoxins and antioxidants: Uncompromising fighting. T-toxin - mechanisms of toxicity and protection. Part 2. Poultry and Poultry Products (Ptiza i Ptizeproducti, Russia) 4: 36-39.

166. Fisinin VI, Surai PF (2013) Immunity in modern animal and poultry production: from theory to practical aspects of immunomodulation. Russian Poult Sci (Ptitsevodstvo, Russia) 5: 4-10

167. Dohms JE, Metz A (1991) Stress--mechanisms of immunosuppression. Vet Immunol Immunopathol 30: 89-109.

168. Antonissen G, Martel A, Pasmans F, Ducatelle R, Verbrugghe E, et al. (2014) The impact of Fusarium mycotoxins on human and animal host susceptibility to infectious diseases. Toxins (Basel) 6: 430-452.

169. Ingrao F, Rauw F, Lambrecht B, van den Berg T (2013) Infectious bursal disease: a complex host-pathogen interaction. Dev Comp Immunol 41: 429 438.

170. Shatskih E, Latipova E, Fisinin V, Denev S, Surai P (2015) Molecular mechanisms and new strategies to fight stresses in egg-producing birds. Agric Sci Technol 7: 3-10.

171. Surai PF, Fisinin VI (2015) Antioxidant-prooxidant balance in the intestine: Applications in chick placement and pig weaning. J Veter Sci Med 3: 16.

172. Mast J, Buyse J, Goddeeris BM (2000) Dietary L-carnitine supplementation increases antigen-specific immunoglobulin $\mathrm{G}$ production in broiler chickens. Br J Nutr 83: 161-166.

173. Janssens GP, Mast J, Goddeeris BM, Cox E, Hesta M, et al. (2000) Enhanced specific antibody response to bovine serum albumin in pigeons due to L-carnitine supplementation. Br Poult Sci 41: 448-453.

174. Deng K, Wong CW, Nolan JV (2006) Long-term effects of early-life dietary L-carnitine on lymphoid organs and immune responses in Leghorn-type chickens. J Anim Physiol Anim Nutr 90: 81-86.

175. Buyse J, Swennen Q, Niewold TA, Klasing KC, Janssens GP, et al. (2007) Dietary L-carnitine supplementation enhances the lipopolysaccharideinduced acute phase protein response in broiler chickens. Vet Immunol Immunopathol 118: 154-159.

176. Geng A, Li B, Guo Y (2007) Effects of dietary L-carnitine and coenzyme Q10 at different supplemental ages on growth performance and some immune response in ascites-susceptible broilers. Arch Anim Nutr 61: 50-60.

177. Parsaeimehr K, Afrouziyeh M, Hoseinzadeh S (2014) The effects of L-carnitine and different levels of animal fat on performance, carcass characteristics, some blood parameters and immune response in broiler chicks. Iranian J Appl Anim Sci 4: 561-566

178. Reza YM, Saeid SS, Javad N (2015) The effects of different levels of L-Carnitine and methionine on immune response and some blood parameters in female broiler. Res Opin Anim Vet Sci 5: 94-98.

179. Khajali F, Khajali Z (2014) L-carnitine supplementation decreases lipid peroxidation and improves cardiopulmonary function in broiler chickens reared at high altitude. Acta Vet Hung 62: 489-499.

180. Abdel-Fattah SA, El-Daly EF, Ali NG (2014) Growth performance, immune response, serum metabolites and digestive enzyme activities of japanese quail fed supplemental I-carnitine. Glob Vet 12: 277-286.

181. Chen YJ, Kim IH, Cho JH, Yoo JS, Wang Q, et al. (2008) Evaluation of dietary L-carnitine or garlic powder on growth performance, dry matter and nitrogen digestibilities, blood profiles and meat quality in finishing pigs. Anim Feed Sci Technol 141: 141-152.

182. Thangasamy $T$, Subathra M, Sittadjody $S$, Jeyakumar $P$, Joyee AG, et al. (2008) Role of L-carnitine in the modulation of immune response in aged rats. Clin Chim Acta 389: 19-24.

183. Izgut-Uysal VN, Agac A, Karadogan I, Derin N (2004) Peritoneal macrophages function modulation by L-carnitine in aging rats. Aging Clin Exp Res 16: 337-41.

184. Izgüt-Uysal VN, Ağaç A, Karadoğan I, Derin N (2003) Effects of L-carnitine on neutrophil functions in aged rats. Mech Ageing Dev 124: 341-347.

185. Elliott GR, Lauwen AP, Bonta IL (1990) The effect of acute feeding of carnitine, acetyl carnitine and propionyl carnitine on basal and A23187stimulated eicosanoid release from rat carrageenan-elicited peritoneal macrophages. Br J Nutr 64: 497-503.

186. Jirillo E, Altamura M, Munno I, Pellegrino NM, Sabato R, et al. (1991) Effects of acetyl-L-carnitine oral administration on lymphocyte antibacterial activity and TNF-alpha levels in patients with active pulmonary tuberculosis. A randomized double blind versus placebo study. Immunopharmacol Immunotoxicol 13: 135-146.

187. Thomas S, Fischer FP, Mettang T, Pauli-Magnus C, Weber J, et al. (1999) Effects of L-carnitine on leukocyte function and viability in hemodialysis patients: A double-blind randomized trial. Am J Kidney Dis 34: 678-687.

188. Berchiche L, Legrand C, Capiaumont J, Belleville F, Nabet P (1994) Effect of $\mathrm{L}$-carnitine and acylcarnitine derivatives on the proliferation and monoclonal antibody production of mouse hybridoma cells in culture. J Biotechnol 34 : 175-183.

189. Ferrara F, Bertelli A, Falchi M (2005) Evaluation of carnitine, acetylcarnitine and isovalerylcarnitine on immune function and apoptosis. Drugs Exp Clin Res 31: 109-114.

190. Winter BK, Fiskum G, Gallo LL (1995) Effects of L-carnitine on serum triglyceride and cytokine levels in rat models of cachexia and septic shock. $\mathrm{Br}$ J Cancer 72: 1173-1179.

191. Ruggiero V, D'Urso CM, Albertoni C, Campo S, Foresta P, et al. (1993) LPSinduced serum TNF production and lethality in mice: effect of L-carnitine and some acyl-derivatives. Mediators Inflamm 2: S43-S50.

192. Arafa HM, Abd-Allah AR, El-Mahdy MA, Ramadan LA, Hamada FM (2003) Immunomodulatory effects of L-carnitine and q10 in mouse spleen exposed to low-frequency high-intensity magnetic field. Toxicology 187: 171-181.

193. Fortin G, Yurchenko K, Collette C, Rubio M, Villani AC, et al. (2009) L-carnitine, a diet component and organic cation transporter OCTN ligand, displays immunosuppressive properties and abrogates intestinal inflammation. Clin Exp Immunol 156: 161-171.

194. Athanassakis I, Mouratidou M, Sakka P, Evangeliou A, Spilioti M, et al. (2001) L-carnitine modifies the humoral immune response in mice after in vitro or in vivo treatment. Int Immunopharmacol 1: 1813-1822.

195. Fattorossi A, Biselli R, Casciaro A, Tzantzoglou S, de Simone C (1993) Regulation of normal human polymorphonuclear leucocytes by carnitine. Mediators Inflamm 2: S37-S41.

196. Delogu G, De Simone C, Famularo G, Fegiz A, Paoletti F, et al. (1993) Anaesthetics modulate tumour necrosis factor alpha: effects of L-carnitine supplementation in surgical patients. Preliminary results. Mediators Inflamm 2: S33-S36.

197. De Simone C, Tzantzoglou S, Famularo G, Moretti S, Paoletti F, et al. (1993) High dose L-carnitine improves immunologic and metabolic parameters in AIDS patients. Immunopharmacol Immunotoxicol 15: 1-12.

198. Abd-Allah AR, Helal GK, Al-Yahya AA, Aleisa AM, Al-Rejaie SS, et al (2009) Pro-inflammatory and oxidative stress pathways which compromise sperm motility and survival may be altered by L-carnitine. Oxid Med Cell Longev 2: 73-81.

199. Sener G, Eksioglu-Demiralp E, Cetiner M, Ercan F, Sirvanci S, et al. (2006) L-Carnitine ameliorates methotrexate-induced oxidative organ injury and 
Citation: Surai PF. Carnitine Enigma: From Antioxidant Action to Vitagene Regulation Part 2. Transcription Factors and Practical Applications. J Veter Sci Med. 2015;3(2): 17.

inhibits leukocyte death. Cell Biol Toxicol 22: 47-60.

200. Moretti S, Famularo G, Marcellini S, Boschini A, Santini G, et al. (2002) L-Carnitine reduces lymphocyte apoptosis and oxidant stress in HIV-1 infected subjects treated with zidovudine and didanosine. Antioxid Redox Signal 4: 391-403.

201. Mosca L, Marcellini S, Perluigi M, Mastroiacovo P, Moretti S, et al. (2002) Modulation of apoptosis and improved redox metabolism with the use of a new antioxidant formula. Biochem Pharmaco 163: 1305-1314.

202. Furuno T, Kanno T, Arita K, Asami M, Utsumi T, et al. (2001) Roles of long chain fatty acids and carnitine in mitochondrial membrane permeability transition. Biochem Pharmacol 62: 1037-1046.

203. Ishii T, Shimpo Y, Matsuoka Y, Kinoshita K (2000) Anti-apoptotic effect of acetyl-I-carnitine and I-carnitine in primary cultured neurons. Jpn J Pharmacol 83: 119-124.

204. Di Marzio L, Alesse E, Roncaioli P, Muzi P, Moretti S, et al. (1997) Influence of L-carnitine on CD95 cross-lining-induced apoptosis and ceramide generation in human cell lines: correlation with its effects on purified acidic and neutral sphingomyelinases in vitro. Proc Assoc Am Physicians 109: 154-163.

205. Ye J, Han Y, Chen X, Xie J, Liu X, et al. (2014) L-carnitine attenuates $\mathrm{H}_{2} \mathrm{O}_{2}$ induced neuron apoptosis via inhibition of endoplasmic reticulum stress. Neurochem Int 78: 86-95.

206. Mao CY, Lu HB, Kong N, Li JY, Liu M, et al. (2014) Levocarnitine protects $\mathrm{H} 9 \mathrm{c} 2$ rat cardiomyocytes from $\mathrm{H}_{2} \mathrm{O}_{2}$-induced mitochondrial dysfunction and apoptosis. Int J Med Sci 11: 1107-1115.

207. Revoltella RP, Dal Canto B, Caracciolo L, D'Urso CM (1994) L-Carnitine and some of its analogs delay the onset of apoptotic cell death initiated in murine C2.8 hepatocytic cells after hepatocyte growth factor deprivation. Biochim Biophys Acta 1224: 333-341.

208. Abd-Allah AR, Al-Majed AA, Al-Yahya AA, Fouda SI, Al-Shabana OA (2005) L-Carnitine halts apoptosis and myelosuppression induced by carboplatin in rat bone marrow cell cultures (BMC). Arch Toxicol 79: 406-413.

209. Bavari M, Tabandeh MR, Najafzadeh Varzi H, Bahramzadeh S (2015) Neuroprotective, antiapoptotic and antioxidant effects of I-carnitine against caffeine-induced neurotoxicity in SH-SY5Y neuroblastoma cell line. Drug Chem Toxicol 1: 1-10

210. Cao Y, Li X, Shi P, Wang LX, Sui ZG (2014) Effects of L-carnitine on high glucose-induced oxidative stress in retinal ganglion cells. Pharmacology 94: 123-130.

211. Liu F, Rainosek SW, Sadovova N, Fogle CM, Patterson TA, et al. (2014) Protective effect of acetyl-L-carnitine on propofol-induced toxicity in embryonic neural stem cells. Neurotoxicology 42: 49-57.

212. Zhang ZY, Fan ZK, Cao Y, Jia ZQ, Li G, et al. (2015) Acetyl-I-carnitineame lioratesmitochondrial damage and apoptosis following spinal cord injury in rats. Neurosci Lett 604: 18-23

213. Wang C, Sadovova N, Ali HK, Duhart HM, Fu X, et al. (2007) L-carnitine protects neurons from 1-methyl-4-phenylpyridinium-induced neuronal apoptosis in rat forebrain culture. Neuroscience 144: 46-55.

214. Sonne S, Shekhawat PS, Matern D, Ganapathy V, Ignatowicz L (2012) Carnitine deficiency in OCTN2-/- newborn mice leads to a severe gut and immune phenotype with widespread atrophy, apoptosis and a proinflammatory response. PLoS One 7: e47729.

215. Shekhawat PS, Srinivas SR, Matern D, Bennett MJ, Boriack R, et al. (2007) Spontaneous development of intestinal and colonic atrophy and inflammation in the carnitine-deficient jvs (OCTN2(-/-)) mice. Mol Genet Metab 92: 315-324.

216. Wu DO, Meydani SN (1998) Antioxidants and immune function. In: Papas AM (ed). Antioxidant status, diet, nutrition, and health, CRC Press, Boca Raton, pp: 371- 400.

217. Williams MS, Kwon J (2004) T cell receptor stimulation, reactive oxygen species, and cell signaling. Free Radic Biol Med 37: 1144-1151.
218. Hildeman DA (2004) Regulation of T-cell apoptosis by reactive oxygen species. Free Radic Biol Med 36: 1496-1504.

219. Kohchi C, Inagawa H, Nishizawa T, Soma G (2009) ROS and innate immunity. Anticancer Res 29: 817-821.

220. Weinberg SE, Sena LA, Chandel NS (2015) Mitochondria in the regulation of innate and adaptive immunity. Immunity 42: 406-417.

221. Hughes DA (1999) Effects of dietary antioxidants on the immune function of middle-aged adults. Proc Nutr Soc 58: 79-84.

222. Conner EM, Grisham MB (1996) Inflammation, free radicals, and antioxidants. Nutrition 12: 274-277.

223. Jourd'heuil D, Morise Z, Conner EM, Grisham MB (1997) Oxidants, transcription factors, and intestinal inflammation. J Clin Gastroenterol 25 Suppl 1: S61-S72.

224. Klasing KC (1998) Nutritional modulation of resistance to infectious diseases. Poult Sci 77: 1119-1125

225. Alesci S, De Martino MU, Mirani M, Benvenga S, Trimachi F, et al. (2003) L-Carnitine: A nutritional modulator of glucocorticoid receptor functions. FASEB J 17: 1553-1555.

226. Alesci S, De Martino MU, Kino T, Ilias I (2004) L-Carnitine is a modulator of the glucocorticoid receptor alpha. Ann N Y Acad Sci 1024: 147-152.

227. Manoli I, De Martino MU, Kino T, Alesci S (2004) Modulatory effects of L-carnitine on glucocorticoid receptor activity. Ann N Y Acad Sci 1033: 147157.

228. Kouttab NM, De Simone C (1993) Modulation of cytokine production by carnitine. Mediators Inflamm 2: S25-S28.

229. De Simone C, Ferrari M, Meli D, Midiri G, Sorice F (1982) Reversibility by L-carnitine of immunosuppression induced by an emulsion of soya bean oil, glycerol and egg lecithin. Arzneimittelforschung 32: 1485-1488.

230. De Simone C, Famularo G, Tzantzoglou S, Trinchieri V, Moretti S, et al (1994) Carnitine depletion in peripheral blood mononuclear cells from patients with AIDS: effect of oral L-carnitine. AIDS 8: 655-660.

231. Baghbanzadeh A, Decuypere E (2008) Ascites syndrome in broilers: physiological and nutritional perspectives. Avian Pathol 37: 117-126.

232. Enkvetchakul B, Bottje W, Anthony N, Moore R, Huff W (1993) Compromised antioxidant status associated with ascites in broilers. Poult Sci 72: 2272 2280.

233. Bottje WG, Wideman RF (1995) Potential role of free radicals in the etiology of pulmonary hypertension syndrome. Poult Avian Biol Rev 6.

234. Arab HA, Jamshidi R, Rassouli A, Shams G, Hassanzadeh MH (2006) Generation of hydroxyl radicals during ascites experimentally induced in broilers. Br Poult Sci 47: 216-222.

235. Bottje WG, Erf GF, Bersi TK, Wang S, Barnes D, et al. (1997) Effect of dietary dl-alpha-tocopherol on tissue and alpha- and gamma-tocopherol and pulmonary hypertension syndrome (ascites) in broilers. Poult Sci 76: 1506-1512.

236. Villar-Patino G, Diaz-Cruz A, Avila-Gonzalez E, Guinzberg R, Pablos JL, et al. (2002) Effects of dietary supplementation with vitamin $C$ or vitamin $E$ on cardiac lipid peroxidation and growth performance in broilers at risk of developing ascites syndrome. Am J Vet Res 63: 673-676.

237. Buyse J, Janssens GP, Decuypere E (2001) The effects of dietary L-carnitine supplementation on the performance, organ weights and circulating hormone and metabolite concentrations of broiler chickens reared under a normal or low temperature schedule. Br Poult Sci 42: 230241

238. Geng A, Guo Y, Yuan J (2004) Effects of dietary L-carnitine and coenzyme Q10 supplementation on performance and ascites mortality of broilers. Arch Anim Nutr 58: 473-482.

239. Tan X, Hu SH, Wang XL (2008) The effect of dietary I-carnitine supplementation on pulmonary hypertension syndrome mortality in broilers exposed to low temperatures. J Anim Physiol Anim Nutr (Berl) 92: 203-210. 
Citation: Surai PF. Carnitine Enigma: From Antioxidant Action to Vitagene Regulation Part 2. Transcription Factors and Practical Applications. J Veter Sci Med. 2015;3(2): 17.

ISSN: $2325-4645$

240. Wang YW, Ning D, Peng YZ, Guo YM (2013) Effects of dietary L-carnitine supplementation on growth performance, organ weight, biochemical parameters and ascites susceptibility in broilers reared under lowtemperature environment. Asian-Australas J Anim Sci 26: 233-240.

241. Yousefi A, Khajali F, Hassanpour H, Khajali Z (2013) Dietary L-carnitine improves pulmonary hypertensive response in broiler chickens subjected to hypobaric hypoxia. J Poult Sci 50: 143-149.

242. Sharifi M, Hassanpour H, Khajali F (2015) Dietary L-carnitine supplement counteracts pulmonary hypertensive response in broiler chickens fed reduced-protein diets and subjected to cool condition and hypobaric hypoxia. J Poult Sci 52: 206-212.

243. Janssens GP, Buyse J, Seynaeve M, Decuypere E, De Wilde R (1998) The reduction of heat production in exercising pigeons after L-carnitine supplementation. Poult Sci 77: 578-584.

244. Celik LB, Tekeli A, Oztürkcan O (2004) Effects of supplemental L-carnitine in drinking water on performance and egg quality of laying hens exposed to a high ambient temperature. J Anim Physiol Anim Nutr (Berl) 88: 229-233.

245. Celik L, Oztürkcan O (2003) Effects of dietary supplemental L-carnitine and ascorbic acid on performance, carcass composition and plasma L-carnitine concentration of broiler chicks reared under different temperature. Arch Tierernahr 57: 27-38
246. Güçlü BK, Kara K, Cakır L, Cetin E, Kanbur M (2011) Carnitine supplementation modulates high dietary copper-induced oxidative toxicity and reduced performance in laying hens. Biol Trace Elem Res 144: 725735

247. Noboukpo KE, Tona K, Agbonon A, Gbeassor M, Buyse J, et al. (2009) Effects of L-carnitine supplementation in drinking water on layer-type chick juvenile performance. Arch Geflügelk 74: 116-120.

248. Jia R, Bao YH, Zhang Y, Ji C, Zhao LH, et al. (2014) Effects of dietary a-lipoic acid, acetyl-I-carnitine, and sex on antioxidative ability, energy, and lipid metabolism in broilers. Poult Sci 93: 2809-2817.

249. Rabie MH, Szilágyi M, Gippert T (1997) Effects of dietary L-carnitine on the performance and egg quality of laying hens from $65-73$ weeks of age. $\mathrm{Br} J$ Nutr 78: 615-623.

250. Velichko O, Surai PF (2014) Effect of an antistress composition supplied with water on chick growth and development. In Proc. XIVth European Poultry Conference, Stavanger, Norway, pp. 551.

251. Fotina A, Fotina TI, Surai PF (2014) Effect of a water-soluble antistress composition on broiler chickens. In Proc. XIVth European Poultry Conference, Stavanger, Norway, pp. 555. 